\title{
Summary of Comments Received at Workshop on Use of a Site Specific Advisory Board (SSAB) to Facilitate Public Participation in Decommissioning Cases
}

Manuscript Completed: June 1995

Date Published: June 1995

Prepared by

J. Caplin, G. Page, D. Smith, C. Wiblin

Advanced Systems Technology, Inc.

932 Hungerford Drive

Rockville, MD 20850

Prepared for

Division of Regulatory Applications

Office of Nuclear Regulatory Research

U.S. Nuclear Regulatory Commission

Washington, DC 20555-0001

NRC Job Code L1618 



\section{DISCLAIMER}

Portions of this document may be illegible in electronic image products. Images are produced from the best available original document. 


\begin{abstract}
The Nuclear Regulatory Commission (NRC) is conducting an enhanced participatory rulemaking to establish radiological criteria for the decommissioning of NRC-licensed facilities. As part of this rulemaking, on August 20, 1994 the NRC published a proposed rule (59 FR 43200) for public comment. Paragraph 20.1406(b) of the proposed rule would require that the licensee convene a Site Specific Advisory Board (SSAB) if the licensee proposed release of the site for restricted use after decommissioning. To encourage comment the NRC held a workshop on the subject of SSABs on December 6, 7, and 8, 1994. This report summarizes the 567 comments categorized from the transcript of the workshop.

The commenters at the workshop generally supported public participation in decommissioning cases. Many participants favored promulgating requirements in the NRC's rules. Some industry participants favored relying on voluntary exchanges between the public and the licensees. Many participants indicated that a SSAB or something functionally equivalent is needed in controversial decommissioning cases, but that some lesser undertaking can achieve meaningful public participation in other cases. No analysis or response to the comments is included in this report.
\end{abstract}





\section{CONTENTS}

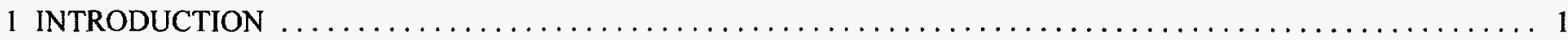

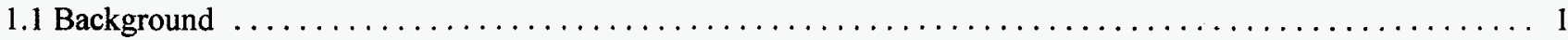

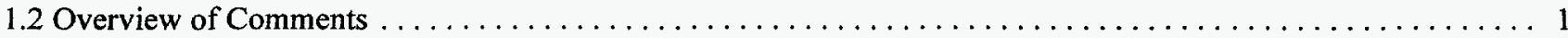

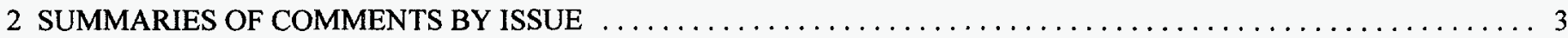

2.1 Site Specific Advisory Boards (SSABs) Versus Other Alternatives $\ldots \ldots \ldots \ldots \ldots \ldots \ldots \ldots \ldots \ldots \ldots \ldots$

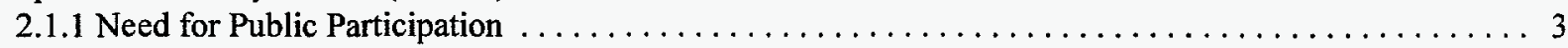

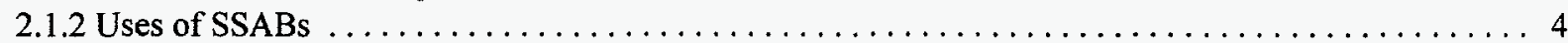

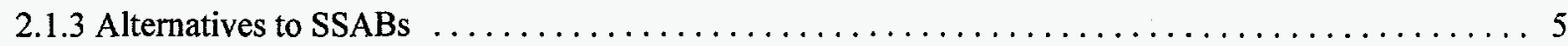

2.1.4 Restricted Release Versus Unrestricted Release Cases $\ldots \ldots \ldots \ldots \ldots \ldots \ldots \ldots \ldots \ldots \ldots \ldots$. . . . . . . . . . 5

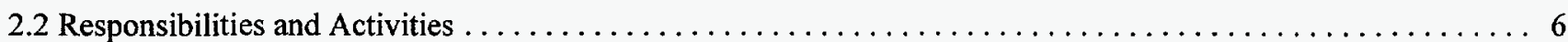

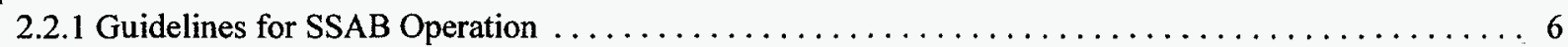

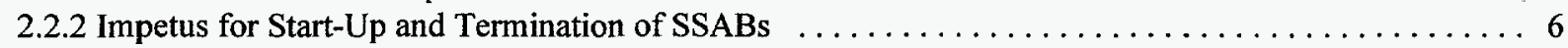

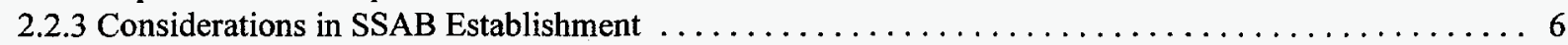

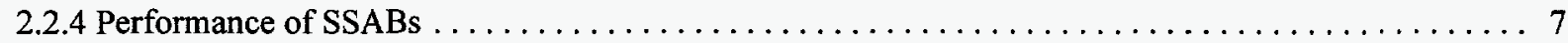

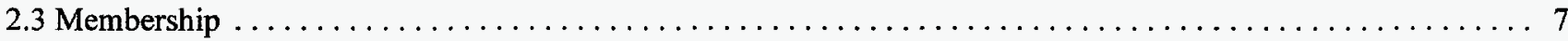

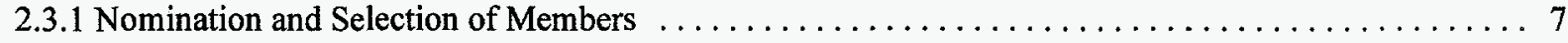

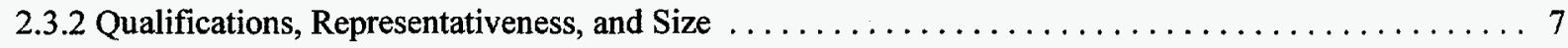

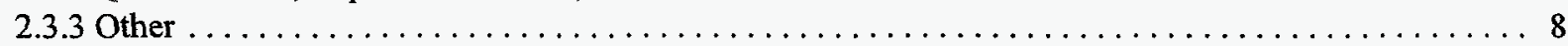

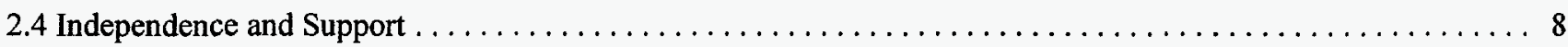

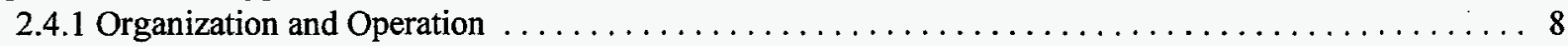

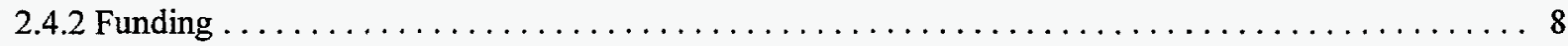

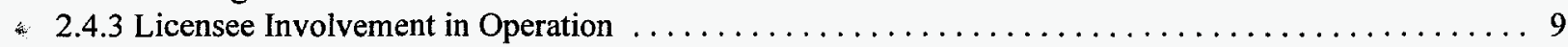

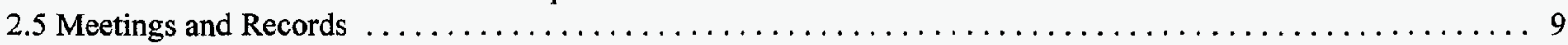

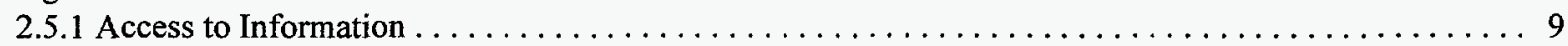

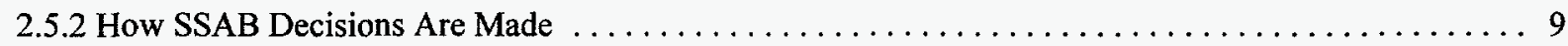

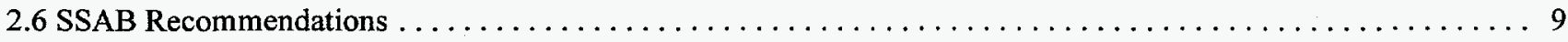

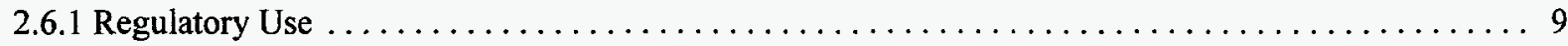

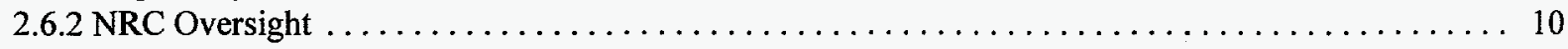

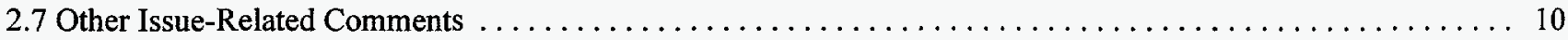

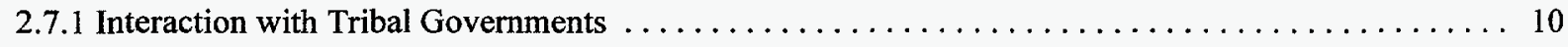

2.7 .2 Interaction with State and Local Governments $\ldots \ldots \ldots \ldots \ldots \ldots \ldots \ldots \ldots \ldots \ldots \ldots \ldots \ldots \ldots \ldots$

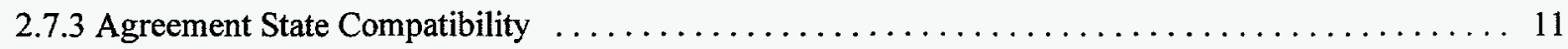

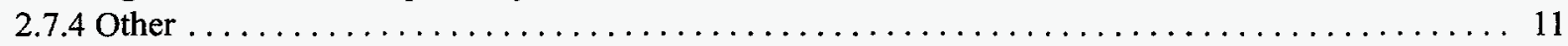

\section{Appendices}

Appendix A Using Licensee Advisory Boards in the Development of Restricted Use

Decommissioning Plans

Appendix B Participants at the Workshop

Appendix C Comment References 


\section{FOREWORD}

The Nuclear Regulatory Commission (NRC) is conducting an enhanced participatory rulemaking to establish radiological criteria for the decommissioning of NRC-licensed facilities. The NRC obtained comments on the scope, issues, and approaches for this rulemaking through (A) a series of seven workshops held from January through May 1993; (B) eight meetings (in four cities) on the proposed scope of the Generic Environmental Impact Statement (GEIS); (C) a dedicated electronic bulletin board system which was established for disseminating information and obtaining comments on the rulemaking; and (D) letters in response to notices in the Federal Register inviting comments.

Copies of the summaries of comments received from this process, published as NUREG/CR-6156, and an NRC "staff draft" proposed rule were distributed to the NRC's Agreement States, participants in the earlier workshops and meetings, and other interested parties for comment. A notice of availability of NUREG/CR-6156 and the staff draft rule was published in the Federal Register, and the documents were placed on the electronic bulletin board. A summary of comments on the draft rule was published as NUREG/CR-6250, and on August 22, 1994, the Commission published in the Federal Register (59 FR 43200) a proposed rule on radiological criteria for decommissioning.

Paragraph 20.1406(b) of this proposed rule requires that a Site Specific Advisory Board (SSAB) be convened when a licensee proposes to request release of the site to a restricted use after decommissioning. On November 4, 1994, the NRC published in the Federal Register (59 FR 55224) a notice of a workshop to be held on the subject of SSABs and of the availability of information pertinent to the workshop. The workshop was held on December 6, 7, and 8, 1994.

The purpose of this report is to summarize the comments categorized from the transcript of the workshop. The comments are being considered by the NRC in developing a final rule on radiological criteria for the decommissioning of NRC-licensed facilities. The results, approaches, and methods described in this NUREG/CR-6307 are provided for information only. Publication of this report does not necessarily constitute NRC approval of, or agreement with, the comments summarized herein.

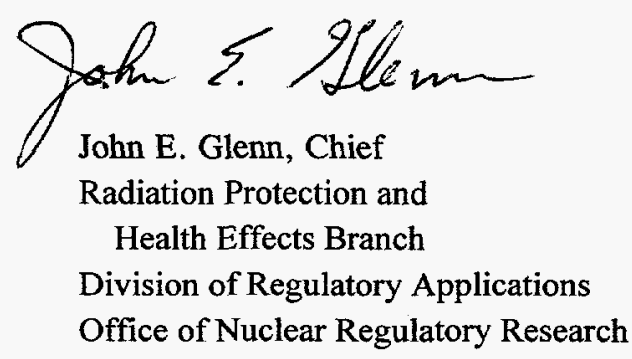




\section{INTRODUCTION}

\subsection{Background}

On August 22, 1994, the Nuclear Regulatory

Commission published for comment a proposed rule on Radiological Criteria for Decommissioning (59 FR 43200). Paragraph 20.1406 (b) of this proposed rule would require that a Site Specific Advisory Board (SSAB) be convened in cases where a licensee requests decommissioning of the site to restricted use. On November 4, 1994, the Commission announced that it would hold a workshop on December 6, 7, and 8, 1994, to discuss the implementation of this requirement with affected parties.

Material presented and used for discussion at the workshops included "USING LICENSEE ADVISORY BOARDS IN THE DEVELOPMENT OF RESTRICTED USE DECOMMISSIONING PLANS" (November 1994), which is in Appendix A. Copies of the transcript of proceedings of the workshop are available for inspection or copying for a fee in the NRC Public Document Room, 2120 L Street, NW, (Lower Level), Washington, DC.

Participants at the workshop and other commenters from the audience are identified in Appendix B along with their addresses and affiliated organizations, as available.

\subsection{Overview of Comments}

There were 567 comments categorized from the workshop. The comments were organized in accordance with the issues and sub-issues identified in Section 2. A comment may relate to more than one issue or sub-issue. The summaries include a total of 1,048 uses for the 567 comments. The summaries are presented with identifying comment numbers, listed in parenthesis. Appendix $\mathrm{C}$ lists the comment numbers, where the comment is used in this report, the last name of the commenter, and the page number where the comment begins in the Transcript of Proceedings.
The commenters generally supported public participation in decommissioning cases. Many participants favored promulgating requirements in the NRC's rules. Some industry participants favored relying on voluntary exchanges between the public and the licensees. Many participants indicated that a SSAB or something functionally equivalent is needed in controversial decommissioning cases, but most believed that some lesser undertaking can achieve meaningful public participation in other cases. The commenters expressed a need for NRC guidance on the formation and functions of SSABs. 



\section{SUMMARIES OF COMMENTS BY ISSUE}

\subsection{Site Specific Advisory Boards (SSABs) Versus Other Alternatives}

\subsubsection{Need for Public Participation}

Commenters appeared to agree that local communities should be given the opportunity to participate in decisions pertaining to the decommissioning of nuclear facilities in their vicinities $(2,14,18,28,33,35,59,82$, $87,88,102,105,107,108,109,111,113,121,157,158$, $196,292,354,357,359,391,392,393,421,504,514)$. Many commenters also agreed that the use of SSABs should perhaps be confined to special cases $(150,153$, $196,221,236,265,376,517,523)$, e.g., after determining by site-specific analysis whether public input is necessary, required or desirable; where citizens request participation; or where there is insufficient "public outreach" by the licensee.

Most commenters recommended that the NRC incorporate public participation requirements in its regulations and specify alternate means of such participation $(6,88,102,107,113,115,153,157,158$, $215,225,226,227,239,252,292,337,386,391,392$, $393,497,519,523,556)$. Commenters cautioned against prescriptive rulemaking $(2,4,18,28,67,84,105,113$, $115,166,229,233,236,250,252,265,283,333,370$, $373,384,513,517,519)$ and recommended that an exemption be provided for certain licensees who possess short half-life, or small quantities of, radionuclides only and for those using sealed sources only $(173,258)$. One commenter cautioned against granting exemptions for small users (190).

Some commenters recommended against the NRC's mandating the extent of required public participation and favored continuation of voluntary actions by licensees to accomplish this $(2,4,11,18,28,108,164,165,166$, $229,250,251,279,286,337,339,340,341,342,345$, $346,347,348,384,385,422,425)$. Other commenters recommended that the NRC take individual case-by-case regulatory actions if licensee voluntary actions are found inadequate $(229,251,422)$. Examples of industry voluntary actions already being taken were cited $(83$,
$209,408,409,502$ ). Still other commenters stated that voluntary actions have not worked satisfactorily (104, $107,109,113,121,157,158,197,220,221,263,275$, $289,292,293,301,340,396$ ). The ultimate goal is to improve the trust and respect between the licensee, the public and community groups, and local governments $(38,465,471,475,504)$, and when the advice of a board is available it improves public trust (43).

Commenters stated that meaningful public participation is more than licensees' and the NRC's simply announcing decisions on decommissioning and expecting the public to accept these without an exchange of views $(6,38,67,75,105,113,145,163,202,203$, $377,379,493)$. It should involve stakeholders' sitting down with decision makers and identifying what decisions they want to be involved in and how issues will be resolved $(88,102,107,109,116,118,130,131,172$, $277,377,379)$. One commenter stressed the need for senior management to be aware of the importance of public participation (82). The NRC rulemaking should address what should be done to achieve meaningful public participation, including education and resources, technical assistance, funding, and facilitation $(29,121$, $126,206,225,226,342,345,386,387)$. The NRC should continue to improve its credibility and should lead in ensuring public participation $(390,459)$.

Several commenters stressed the importance of the NRC's and licensees' participating in efforts to educate local communities in the mechanisms for decommissioning nuclear facilities long before the decommissioning is to start and in efforts to provide opportunities for local communities to express their concerns; an infrastructure for meaningful public participation will need to be established with the assistance of the NRC and licensees $(4,9,25,29,33,35$, $102,103,119,138,199,202,203,207,213,226,239$, $272,277,278,314,315,340,341,354,371,498,501$, $505,506,518$ ).

Some commenters raised questions about, and addressed the subject of, how greater public participation might affect litigation in cases involving the decommissioning of nuclear facilities $(24,135,139,140,141,155,158$, 
$163,167,169,172,179,181,187,237,239,319,382$, $383,389,531)$.

\subsubsection{Uses of SSABs}

Many commenters opposed, or expressed reservations about, the NRC's mandating the use of SSABs as specified in the NRC's proposed rulemaking $(2,3,5,10$, $17,31,61,65,67,84,85,86,106,127,149,196,211$, $252,337,342,345,346,365,422,425)$. The comments included:

- $\quad$ Advisory boards should be seriously considered but their use should not be mandated. The boards might be one of several means of achieving effective public involvement $(17,61$, $65,67,84)$.

- What is important is public involvement in the process and decisions. A board should not be prescribed for all sites. If a licensee has a successful outreach program, then we should not fix anything that is not broken $(196,252)$.

- $\quad$ As structured in the proposed rule, with vagaries and lack of specifics, the SSAB might chill, rather than enhance, public outreach ( 31 , 85).

- $\quad$ Mandating SSABs could cause more public concern and frustration because of poor risk communication (425).

- $\quad$ Setting up an advisory board involves a process and bureaucracy, operating without a quality assurance plan, that could slow down and frustrate the people who want to be involved in the decisions $(86,346)$.

- $\quad$ Over time, advisory boards tend either to disintegrate or to assume without authority an oversight role. The boards become suspect to the parties they are representing $(61,211)$.

- An informal poll of some environmental organizations showed a range of responses from favorable to hostile about their experiences with advisory boards (5).

- The NRC should work with the licensee and the community to make existing processes work more effectively (422).

- $\quad$ Advisory boards for federal facilities might not be appropriate models for non-federally owned facilities. How money is spent on federal sites might not bear much resemblance to how it can be spent at private sites $(2,127,365)$.

- $\quad$ The concept of mandating the use of SSABs infringes on rights of licensees to manage their own affairs when they are operating in accordance with laws (3).

- The NRC might not have the legislative authority to tell private enterprise how they must interact with the local community (106, 152).

- There is resentment over federal mandates, particularly non-funded mandates, for handling state and local issues $(337,342)$.

- $\quad$ SSABs could take away from state and local officials and others the ability to interact and provide meaningful comments to the NRC (345).

- $\quad$ Keep the real world in perspective and make sure that regulations that are written are necessary $(10,149)$.

One commenter asked if the NRC has the incentive to establish an SSAB if the licensee lacks that incentive (166).

Many other commenters favored the NRC's promulgating a requirement to use $\mathrm{SSABs}$ or some other designated board $(22,29,32,33,34,37,95,104,111$, $119,126,129,197,221,225,254,268,283,290,294$, $300,303,306,311,332,393,546,555)$. Most of those favoring use of SSABs said they would not insist on their use in all cases as long as the NRC promulgates other requirements which ensure meaningful public involvement and accountability for community concerns $(225,227,393,421)$. However, in some cases, an SSAB or its functional equivalent will need to be established and the NRC should provide suitable guidance and appropriate rulemaking to ensure its use when needed $(49,74,105,107,114,197,175,221,225,226,227$, $239,242,254,271,290,294,300,303,306,311,333$, $386,393,421,431,556)$. Arguments were made both for $(24,33,38,62,63,78,111,126,271,303,306,311$, $332,351)$ and against $(15,30,31,56,58,61,62,64,78$, $80,86,87,90,141,147,149,211,212,233,234,252$, $285,286,287,347,348,350,357,502)$ the use of SSABs.

Commenters said that SSABs, or their functional equivalents, should be used to advise licensees and that 
the NRC should maintain oversight to ensure that legitimate public concerns are properly addressed (116, $118,123,168,172,199,221,225,226,303,306,309$, $311,320,321,333,358)$. One commenter (154) stated that the SSAB should advise the licensee on environmental restoration issues and health issues but should not be involved in the licensee's day-to-day business. Another commenter stated that the SSAB should give advice only and that the advice should be given to the licensee, the NRC, and state and local governments (162). One stated that the SSAB should advise the $\mathrm{NRC}$, the regulator, because this rule is about terminating the license (543). Some commenters raised questions about whether an SSAB would need to be constituted under the Federal Advisory Committee Act (FACA). See discussion in paragraph 2.6.1.

Several commenters recommended that the rulemaking provide that an SSAB, or its functional equivalent, be established if citizens or a local or state government requests the NRC to take this action $(24,89,153,245)$. Some commenters suggested that the NRC hold something akin to a scoping meeting to decide whether an SSAB or a lesser structure should be employed at a particular site $(25,372,473)$. One commenter suggested that the issue of whether or not to establish an SSAB should be placed on a local referendum (339).

\subsubsection{Alternatives to SSABs}

Most commenters recommended that the NRC promulgate generic performance-based requirements for ensuring effective public participation, and describe alternative mechanisms and acceptance criteria for meeting these requirements in a regulatory technical position or guide $(6,9,115,153,161,197,199,215$, $220,224,227,239,252,376,386,494,519,556)$. One acceptable means for achieving needed public participation would be to establish an $\operatorname{SSAB}(115,207$, 227). One commenter noted that, for federal facilities, advisory boards are not intended as the only means of citizens' input (23).

Many commenters recommended that licensees be required to prepare a public participation plan and submit it to the NRC for approval $(115,133,153,161$, $207,215,227,339,376,421,435,449,493,494,495$, $496,497,513,514,523,525)$. The plan would talk about mechanisms for public participation, including resources (133) available for this purpose. (See also paragraph 2.1.1.) Some commenters recommended that a public participation plan not be required in all cases $(173,515)$. (See also paragraph 2.1.1 regarding a proposed exemption for designated facilities).

One commenter indicated that where licensees have worked closely with the people in the local community and have established long relationships of trust with the local community, an SSAB might not be needed (350).

Commenters suggested that there be one or more prelude discussions in the community to give notice to, and enable the public to participate knowledgeably in, the creation of the licensee's plan $(133,138,386)$. (See also paragraph 2.1.1, needed educational efforts.)

\subsubsection{Restricted Versus Unrestricted Release}

\section{Cases}

Many commenters urged the NRC to promulgate public participation requirements for both restricted and unrestricted release cases $(9,24,52,104,110,112,126$, $144,148,150,153,159,171,216,222,263,267,276$, $293,294,518,524,525,546,547)$. What is needed in one case will not necessarily be needed in all other cases $(110,112,114,115,116,222,256,280,386,546)$, e.g., because of the wide variance in conditions between a small medical facility and a power reactor, or the involvement of sensitive lands, a particular social setting, or tribal lands.

Some commenters expressed reservations about the restricted release of contaminated sites $(182,216,275$, 304,562 ). One commenter suggested that there be a time limit on how long sites will need restrictions applied $(52,182)$, and that local communities be involved in decisions on whether a site should be given restricted release or unrestricted release (148). A commenter noted a need for regulatory balancing to ensure that the requirements for restricted release not promote the creation of active waste management sites (359). 


\subsection{Responsibilities and Activities}

\subsubsection{Guidelines for SSAB Operation}

Commenters recommended that the NRC establish clear guidelines on the mission of SSABs and on the procedural aspects of their operation $(31,97,130,175$, $176,180,198,199,210,220,224,239,246,321,333$, 358,361 ). Several cautioned that the NRC should not prescribe tight ground rules, but should permit SSABs to have wide latitude in establishing and carrying out their charter $(41,51,60,117,118,122,126,130,131,141$, $154,200,270,333,375,502)$. Some said that it would be difficult or inappropriate to tightly limit what an SSAB may do $(51,56,76,116,141,176,180,269,270$, $330,333,350)$.

Many comments were offered on specific activities that an SSAB should or should not be permitted to become involved in $(25,42,46,51,148,175,182,183,185,186$, $193,194,210,318,325,327,328,329,330,331,352$, 409, 426). Acceptable activities included educating the community; disseminating information; determining the appropriateness of restricted or unrestricted release; decommissioning methods; dose assessment models, scenarios and calculations, ALARA efforts and how clean is clean; approving the accuracy of sampling and measurement methods; and institutional controls. Activities mentioned for exclusion were for example matters which infringe upon existing authorities and responsibilities; adequacy of existing regulations; how clean is clean; future site ownership; and matters not subject to licensees' authority to control.

A few commenters recommended that an SSAB be required, early on, both to develop an action plan to define what decisions it will focus on and provide advice on, and to provide a time scale for when decisions will be made $(68,69,70,92,99,100,133,146,200,422)$.

Most commenters agreed that SSABs should be advisory only and that their recommendations should not be binding $(14,19,22,35,42,57,59,109,123,156,162$, $168,172,177,302,320,321,325,333,347,521)$. Many felt that the NRC should require that all SSAB recommendations be fully considered for implementation $(71,121,123,126)$, and carefully guard against the perception that decision-making is a joint
NRC/licensee/public responsibility (302). One commenter recommended that SSABs make their recommendations directly to the NRC (543).

A commenter recommended that SSABs publish and distribute a periodic newsletter to inform the community of SSAB activities and what they are deciding (413).

\subsubsection{Impetus for Start-Up and Termination of SSABs}

Most commenters stated that SSABs should be considered for start-up before decommissioning begins $(25,120,138,151,240,247,257,277,306,341,354$, $360,405,411,430,499,501,523,546)$. It is important for the NRC and licensees to participate in educational efforts early on to prepare an infrastructure for communities to decide if they want an SSAB established $(25,72,87,94,119,203,207,208,226,239,240,253$, $266,273,315,340,371,372,421,428,434,466,493$, 501). Some commenters offered specific suggestions as to when or how SSABs might be started up $(153,245$, $366,368,381,403,420,533,558,559)$, e.g., when a reactor "officially" shuts down; intermittently, as required, until site "release;" when there is a plan "that outlines" decommissioning; at a specified time before the "scheduled license expiration date;" on receipt of a decommissioning plan pursuant to $\S \S 20.1405$ and 20.1406; upon petition from a community or upon a request from a government agency; or when the NRC believes it is needed.

Others suggested that more study and development is needed $(363,375,497)$.

Sunset expectations need to be addressed when SSABs are created, but ending dates are hard to give, because these are influenced by what decommissioning actions are ultimately taken and by whether long-term monitoring may be needed $(56,69,356,368)$.

\subsubsection{Considerations in SSAB Establishment}

Many commenters recommended that the NRC take the lead in deciding when an SSAB should be established and in taking the necessary steps to get it organized (217, $244,248,274,277,278,291,369,428,429,445,464$, $489,498,559)$. Several recommended that the NRC not 
directly establish SSABs, but rather appoint an independent convener to make recommendations to the NRC on membership and organization $(360,388,428$, $429,430,432,441,442,443,472,477)$. Still other commenters recommended against licensees taking the lead in convening and leading the operation of SSABs $(3,217,244,248,274,277,278,419,428,430,445$, $464,559)$. Other commenters recommended that SSABs be convened by a joint effort of licensees, the NRC, local governments, and key community organizations in some combination $(138,300,434,448,452,493)$. Some commenters cautioned against relying on state and local governments to convene an $\operatorname{SSAB}(262,264,428,489)$.

Some commenters recommended that the NRC be a member of SSABs and help to facilitate their effective operation $(41,397,432,464,468,557,559)$. One commenter recommended that tribal governments be permitted, but not be required, to be members of SSABs (147). Also, it was recommended that the NRC address what actions it will take when an Agreement State is involved and the state is negligent in ensuring public participation (261).

Some commenters recommended that licensees, the $\mathrm{NRC}$, and local governments address monetary and technical assistance resources required by an SSAB at the time it is established $(137,300,495)$.

\subsubsection{Performance of SSABs}

Commenters recommended that the NRC continually assess the ongoing performance of SSABs in an effort to ensure that they are working satisfactorily and that improvements are made as needed $(27,50,60,73,77$, $91,93,101,128,129,172,174,291,439)$.

\subsection{Membership}

\subsubsection{Nomination and Selection of Members}

A few commenters recommended that whenever it is decided to establish an SSAB, the NRC appoint a neutral convener or ad hoc committee to nominate its members $(48,360,415,428,432,435,440,451,462,463,469$, $472,477,478,479,534,538)$. See discussion also in paragraph 2.2.3. Commenters also suggested that the
NRC consider holding a meeting akin to a scoping meeting to assist the neutral convener to identify interested parties $(473,474,475,476)$.

Commenters recommended that the NRC consider the nominations recommended by the neutral convener and that the NRC appoint members to the SSAB $(440,468$, $469,476,477,480)$. Two commenters recommended against state and local governments deciding who will sit on the SSABs $(264,400)$.

Some commenters indicated that members may need to be selected in accordance with the Federal Advisory Committee Act (FACA) $(79,507,508$ ). (See also paragraph 2.6.1). One commenter suggested the need for a procedure for getting placed on an SSAB or being accepted as a member (395).

\subsubsection{Qualifications, Representativeness, and Size}

Commenters recommended that the NRC develop and publish guidelines for membership, such as provided in the Keystone Document, but that these should not prescribe who the stakeholders are to be $(136,175,198$, $269,270,361,394,396,397,412,470)$. The NRC should emphasize the importance of SSAB membership and encourage individuals to seek appointments (406, 411).

Some commenters recommended that members perhaps be selected to assure each SSAB maximum expertise in solving anticipated problems $(44,53,98,99,253,458$, 505). Other commenters said that membership and problem-solving do not need to be matched, because an SSAB can bring in outside consultants when these are needed $(192,427)$. Other commenters suggested that prospective members commit themselves to appropriate training and that the NRC discourage those who are unwilling $(436,439,503)$. One commenter stated that two or three days up front should be invested in training in team-building and dispute-resolution techniques (72).

With respect to representative membership, commenters recommended that special consideration be given to members of the community most affected by the decommissioning, particularly those in effluent pathways $(26,36,188,200,397)$. All the communities and people 
should be represented on the SSAB $(175,255,553)$.

Membership should be diverse $(125,225,394,401,411$, $446,542,544)$ and include people who do not have preconceived biases as well as those who may have them $(34,36,415,424,529,551)$. Many recommendations were offered on the kinds of people who might be good to have on boards $(313,395,397,404,410,433,444$, $446,454,540,548,551,564)$. In addition, commenters suggested encouraging minority groups to participate to assure environmental justice $(39,54,255,394,539)$.

Commenters said that membership might need to be limited with respect to size to facilitate informal discussions and exchange of views $(47,399,407,416)$. If SSABs are limited in size, the NRC should select alternatives and replacements (48) should another population need to be represented on the SSAB after the initial selections are made (438). Many commenters suggested that membership be open to everyone who has an interest in serving on the SSAB $(175,230,269,274$, $276,335,380,402,409,417,486)$. Another commenter suggested appointment of a smaller executive committee to make decisions $(486,487)$.

Commenters recommended that tribal, state, and local governments be invited to participate on boards but not be required to do so $(147,188,189,205,238,243,316$, $317,324,342$ ). Elected officials' or government representatives' sitting on the boards should not affect how the NRC deals government-to-government with the Indian tribes, the states, and the local governments (374). Some commenters questioned whether these participants should have full membership or should have ex officio status $(355,374,397,450,469)$.

Commenters also recommended that the NRC be a member of SSABs $(397,432,464,468,557,559)$. One commenter expects the SSAB process to be a bureaucratic nightmare, so the NRC should participate on the SSABs in order to develop trust (557).

\subsubsection{Other}

With respect to whether members should be seated as individuals, a commenter said that it is unreasonable to expect members to speak authoritatively in all instances for their affiliated organizations; accordingly, members should be seated as individuals and be expected to keep their organizations informed on SSAB deliberations $(509,535)$.

One commenter noted that where the population is small the SSABs and similar restoration advisory boards (such as used by military installations) might have nearly identical memberships (423).

A commenter indicated that in one community local legislation provided for an advisory board on decommissioning. Though this board was designed to be as democratic as possible, it might have diminished the influence of particular groups (241).

\subsection{Independence and Support}

\subsubsection{Organization and Operation}

Commenters recommended that SSABs be independently established $(3,40,41,45,117,217,248$, $274,419,428,430,445,462,472,483,528,550)$ and permitted to have their own ground rules $(41,126,200$, 375) (See discussion also in paragraph 2.2.1).

SSABs will need to be provided assistance in organizing and structuring their operation and in bringing in technical experts $(29,32,78,80,178,192,272,326$, $330,352,436,437,457,481,482,490,491,537)$. Commenters cautioned that there should be restrictions on the kinds of outside technical consultants brought in $(455,552)$ and suggested that the NRC provide technical experts where appropriate $(214,235,458,530)$.

Commenters said that all voices should be heard and disagreements should be recorded $(178,272,369)$.

Several commenters recommended that decision-making of SSABs be coordinated with the local government $(134,453,456,487,490,491,500)$.

\subsubsection{Funding}

Commenters indicated that operation of an SSAB will require a lot of money $(64,78,80,127,143,195,511$, 512). There was disagreement on whether SSABs are worth their cost $(201,206,286,319,322,323,455$, 554). Commenters agreed that adequate funding must be 
provided to permit SSABs to operate effectively $(5,26$, $29,32,41,121,126,133,137,192,198,225,260,300$, $323,326,334,338,342,352,388,411,435,481,489$, 537). Commenters cautioned that costs should be carefully considered by an SSAB before dollars are allocated $(286,326,515,532,552)$.

Many comments were offered concerning where resources should come from to fund SSABs, including from the industry, local communities and the federal government, and possibly a shared responsibility $(19,96$, $127,134,143,192,195,235,288,343,447,453,460$, $461,467,484,495,503,510,511,520,532,552,563$, $565)$.

\subsubsection{Licensee Involvement in Operation}

Although licensees should not convene and run SSABs, as discussed in paragraph 2.2.3, commenters recommended that licensees be actively involved in SSAB operations $(96,192,201,449,550)$. At an early point in the meeting, a commenter suggested that licensees run the SSABs (96). Commenters favored SSABs' making recommendations to licensees (123, $154,156,174)$, but some suggested that the recommendations be made to the $\operatorname{NRC}(349,505,543)$.

Commenters recommended that licensees involve their senior management in dealing with SSABs $(66,83,98$, 539)

\subsection{Meetings and Records}

\subsubsection{Access to Information}

Commenters stated that a licensee should be required to provide an SSAB with all information it has that is important to decommissioning the nuclear facility ( 21 , $188,260,303,308,383,407,485,560$ ). One commenter identified specific types of information that should be included (485), e.g., radiological and nonradiological sampling data, scientific validity of measurement methods, or information to show compliance with laws; and other commenters indicated that the information made available should be transparent and understandable even to disadvantaged social and economic groups $(55,202,336)$.
Some industry commenters expressed concern that open and frank discussions with SSABs could increase licensee litigation risks $(139,140,382,531)$. One commenter indicated that openness could decrease litigation risks (319). See also discussion in paragraph 2.1.1.

Commenters recommended that SSAB meetings be made public and that a record of what is discussed should be kept available for public inspection $(55,59,73,336$, $398,413,487$ ). Also, newsletters should be considered as a means of keeping local communities informed (413).

One commenter advised that SSABs be required to keep a record of all their activities, particularly those involving the expenditure of money (73).

\subsubsection{How SSAB Decisions Are Made}

Commenters recommended that SSABs at the outset clearly define what licensee decisions they want to be involved in, who will be making these decisions, and what role the SSABs want to have $(51,58,68,70,97$, $99,100,122,146,422)$. There needs to be a dialogue and not simply a notice to the SSAB of what actions are being planned or have taken place $(7,38,172,272)$. Commenters stated that what is important is citizen input and that voices be heard; it is less important that consensus on all matters be reached $(22,25,38,60,178$, $272,274,326,361,362,378,380,462,535)$.

Some commenters recommended that SSAB decisions be determined by SSAB vote while others recommended decision-making by consensus, or, where this is not possible, permitting a voicing of all points of view (178, $361,364,378,380,487,492,535$ ).

\subsection{SSAB Recommendations}

\subsubsection{Regulatory Use}

Commenters suggested that SSAB recommendations be directed to licensees, and that these should be advisory only $(109,123,154,156,162,168,172,174,320,321$, 
325). Other commenters questioned if the recommendations should not instead be directed to the $\mathrm{NRC}$, since the NRC is ultimately responsible for determining if licensee actions are required $(4,162,244$, $349,505,507,543)$. The distinction of who should receive and act on the recommendations is important in deciding if SSABs should be constituted under the Federal Advisory Committee Act (FACA) (4, 79, 154, $162,166,349,507,508,536,543,565)$. Commenters stated that licensees should be required to address each recommendation and inform the SSAB of actions they plan to take, if any, and of reasons for not doing what the SSAB recommended $(7,66,71,124,172,330,378)$.

Commenters suggested that SSAB recommendations perhaps be jointly considered by licensees, the NRC, and other government agencies, and that each respond with respect to recommendations which fall under its jurisdiction $(123,210,291)$. A commenter recommended that the $\mathrm{NRC}$ not give a higher weighting to SSAB recommendations than to those received from other stakeholders such as tribal governments (344).

\subsubsection{NRC Oversight}

Commenters recommended that $\mathrm{SSAB}$ activities be continually assessed and that SSABs be asked to notify the NRC when things are not going well $(27,73,77$, $101,545)$. Other commenters recommended that the NRC maintain an effective oversight of SSAB performance by tracking SSAB recommendations and licensee response actions $(71,81,91,96,174,225,244$, $248,336,377,432,464)$. Commenters indicated that in the final analysis the NRC must decide the acceptability of licensees' decommissioning plans $(13,57,109,277$, $291,302,521$ ).

Some commenters suggested that evaluations of SSAB performance might be carried out by an independent third party $(101,121)$.

\subsection{Other Issue-Related Comments}

\subsubsection{Interaction with Tribal Governments}

Commenters stated that tribal governments should be permitted, but not necessarily required, to be members of SSABs $(147,188,189,191,205,218,238,243,324$, $331,374)$.

SSABs are not an appropriate substitute for one-on-one interactions between the federal government and tribal governments as required by treaty $(145,160,169,204$, $218,219,223,238,243,259,374)$. Commenters indicated that the NRC must interact with tribal governments as sovereign governments and that this requires much more than the NRC's listening to tribal comments and then doing what it wants to do $(1,15,16$, $20,21,131,132,145,188,260)$. One commenter stated that, unless an extensive tribal consultation process takes place on this NRC rulemaking, it will not be acceptable to tribal governments $(561,562)$. Another commenter suggested that the NRC come up with a tribal participation policy and plan which is separate and apart from a public participation policy, adding that this should umbrella all of the NRC's activities (566). One commenter recommended that tribal participation be specified in the NRC regulations (132). One commenter noted the NRC's stated intent to notify tribal governments of its receipt of licensees' decommissioning plans (12).

Some commenters suggested that appropriate tribal participation could be patterned after that required by the Nuclear Waste Policy Act, as amended in 1987, and appropriately changed to reflect recent changes affecting tribal rights $(15,161,184,185)$.

Commenters recommended against state and local governments convening SSABs and taking a lead in arranging tribal participation $(132,262,264,400,527)$. 
Comments were also made that the NRC should not give higher weighting to SSAB recommendations than to tribal recommendations $(344,345)$.

\subsubsection{Interaction with State and Local Governments}

Commenters noted that a special relationship exists between federal, state, tribal, and local governments (374). Whether or not state and local governments should be full members of SSABs or ex officio members should depend on whether they have a regulatory role at the site $(355,374)$. One commenter recommended that the Nuclear Waste Policy Act, as amended in 1987, should be a point of reference for how state, tribal, and local governments should interact with the federal government (161).

Most commenters recommended that local governments have a key role in SSAB activities $(94,134,143,232$, $253,273,290,291,296,316,360,373,387,390,408$, $452,456,487,490,491,500)$. One commenter questioned the local government's role in the regulation of nuclear material since federal jurisdiction has long been asserted (295). Commenters said that local governments have more than an advisory role in certain decision-making involving decommissioning of nuclear facilities, particularly in decisions involving proposed restrictions on land use $(33,94,95,117,170,223,231$, $253,273,282,284,295,297,298,317,373)$.

Commenters cautioned against the NRC's mandating extensive local government involvement in SSAB activities unless necessary funding is provided to assist governments in carrying them out $(149,284,300,322$, $334,337,342,345,387,456,489,495)$.

Some commenters recommended that local and state governments have a role in the creation of public participation plans $(133,161)$ and one suggested that the local government might start the process (547).
Other commenters advised that state and local governments not be relied upon to adequately represent tribes $(132,262,400,527)$.

One commenter recommended that SSAB recommendations be sent to state and local governments, in addition to licensees and the NRC; and government agencies should take action on any recommendations falling under their jurisdiction (123).

One commenter said that the NRC should assist in coordinating state and local government requirements (281).

\subsubsection{Agreement State Compatibility}

Commenters recommended that the NRC work with the Agreement States in deciding how the rulemaking is to be applied in terms of required compatibility and how uniform the decommissioning of nuclear facilities must be on a nationwide basis $(152,219,228,516,526,563)$.

One commenter requested that the NRC's rulemaking address what role it will take if a state is negligent in decommissioning cases involving Agreement State licensees (261).

\subsubsection{Other}

Commenters emphasized the need for the NRC to play a more active role in going out to communities to help explain the decommissioning process $(213,314,341$, $459,465,505,506$ ). Some commenters cautioned that the NRC's educational efforts should have citizen input and be a balanced presentation $(367,369,371,390$, 391). One commenter suggested that the NRC should conduct research on how "training the community" would best be accomplished (444).

Commenters stated that some members of a community might feel intimidated in coming out and raising issues, 
and recommended that the NRC step in and deal with it when it occurs $(411,414,418,419)$.

Several individuals provided comments on the NRC's proposed standards for the restricted release of sites with respect to the prescribed dose limit range of 15 to 100 millirem and for the length of time a site must remain restricted $(52,193,213,214,249,299,307,359)$. Other commenters questioned the desirability of grandfathering sites previously decommissioned $(353,488)$. Some commenters noted that the NRC's "timeliness rule" imposes time constraints on public input to decommissioning plans $(348,567)$.

Other comments included:

- The NRC's decommissioning actions must protect future generations and be recorded for future reference (8).

- Decommissioning should be addressed before you have a license and the associated costs should be a licensing consideration $(305,310$, 311, 312).

- Cleanup of chemical toxicants should be addressed by SSABs (327).

- SSABs should consider health effects to communities where nuclear materials are ultimately stored or disposed of $(328,329)$.

- The NRC's public participation requirements should not be placed in 10 CFR Part 20 but rather should be in other parts of the NRC regulations (522).

- The NRC should not apply its clean up standard as a reuse or recycle standard (549).
- The proposed rulemaking is lacking in the definitions section; more definitions are needed to improve clarity (558).

- Whatever is done should be cost effective (512).

- At DOD bases there are, separate from and in addition to advisory boards, reuse committees on future use of the property (541). 


\section{APPENDIX A}

USING LICENSEE ADVISORY BOARDS IN THE DEVELOPMENT OF RESTRICTED USE DECOMMISSIONING PLANS 


\section{USING LICENSEE ADVISORY BOARDS IN THE DEVELOPMENT OF RESTRICTED USE DECOMMISSIONING PLANS}

Issues for Discussion at a

Workshop Held December 6-8, 1994

Washington, D.C.

by

Mary R. English ${ }^{1}$, David L. Feldman', Donald G. MacGregor ${ }^{2}$, Mary B. Swanson ${ }^{1}$, Bruce E. Tonn ${ }^{3}$

${ }^{1}$ Energy, Environment and Resources Center, University of Tennessee, Knoxville;

${ }^{2}$ MacGregor-Bates, Inc.; ${ }^{3}$ Oak Ridge National Laboratory 
APPENDIX-A

TABLE OF CONTENTS

Section

Page

SUMMARY

NEED FOR OBTAINING TIMELY INPUT FROM AFFECTED PARTIES

PORTIONS OF THE PROPOSED RULE PERTAINING TO LABS

BACKGROUND

Existing Requirements: Public Participation and Environmental Justice

Site-Specific Advisory Groups: A Possible Model?

Lessons for LABs

Number and Types of NRC Licensees

Applicability of $\mathrm{LAB}$ requirement

ISSUES FOR DISCUSSION

Issue 1. What specific functions and underlying purposes should a LAB serve?

Issue 2. What are the general objectives of a $\mathrm{LAB}$, and how can they be achieved?

Issue 3. What implementation details need to be considered when establishing a LAB?

Issue 4. In the Commission's rulemaking concerning LABs, is a prescriptive or performance-based approach preferable?

Issue 5. Are there special conditions under which a LAB might not be appropriate, where another organization could be used, or where participation by some members would be impeded? Are there special conditions under which a $\mathrm{LAB}$ should be required, even though the LAB requirement would normally not apply?

Issue 6. How should the effectiveness of LABs be evaluated, and what are the regulatory implications of $\mathrm{LAB}$ evaluations? 


\section{SUMMARY}

This paper discusses issues associated with establishing advisory boards as a means of increasing stakeholder participation in the decommissioning plans for facilities licensed by the U.S. Nuclear Regulatory Commission (NRC). NRC's Proposed Rule on Radiological Criteria for Decommissioning of August 22, 1994, proposes to require that Site-Specific Advisory Boards (SSABs) or equivalent bodies be established to provide early public involvement in the development of restricted use decommissioning plans. In this paper, these boards are referred to as Licensee Advisory Boards (LABs), to avoid confusion with existing SSABs that have somewhat different purposes.

The paper begins with a discussion of existing and proposed NRC public participation requirements. Current NRC regulations permit public participation through document review, public hearings, and public comment. However, NRC's enhanced participatory rulemaking process has concluded that the available means of stakeholder involvement should be enlarged to increase the participation of affected parties in the decommissioning process; to ensure equal protection for individuals, especially rural populations, low-income groups, and people of color; and to protect the environment.

Following the discussion of the Commission's existing and proposed public participation requirements, there is a brief account of other agencies' and private sector organizations' experience with LAB-type bodies. The U.S. Department of Energy (DOE) and the U.S. Department of Defense (DOD) have established LAB-type boards in order to incorporate stakeholder concerns in environmental restoration, waste management, and facility closure issues. In addition, states, at the behest of the U.S. Environmental Protection Agency, have required the establishment of Local Emergency Planning Committees in order to incorporate stakeholder input in plans designed to protect communities from the hazards of accidental chemical releases.

Further, other public and some private-sector organizations, most notably within the chemical and electric power industries, have established citizen advisory boards in order to incorporate stakeholder input in facility operations, to improve community relations, and to encourage innovative suggestions for reducing risk.

Most of these LAB-type groups are far too recent to be definitively evaluated. However, general lessons of potential importance to LABs include the need for a clear statement of the advisory group's purpose in order to avoid misunderstanding, ensuring the group's independence to protect its credibility, matching member expertise with the problem at hand, and familiarizing members with the facility's operations.

The remainder of the paper presents a series of issues, sub-issues, and associated questions designed to serve as a basis for discussion at a December 1994 NRC-sponsored workshop. The issues are:

- What specific functions and underlying purposes should a LAB serve? 


\section{APPENDIX-A}

- What are the general objectives of a $\mathrm{LAB}$, and how can they be achieved?

- What implementation details need to be considered when establishing a LAB?

- In the Commission's rulemaking concerning LABs, is a prescriptive or performance-based approach preferable?

- Are there special conditions under which a LAB might not be appropriate, where another organization could be used, or where participation by some members would be impeded? Are there special conditions under which a $\mathrm{LAB}$ should be required, even though the LAB requirement would normally not apply?

- How should the effectiveness of LABs be evaluated, and what are the regulatory implications of LAB evaluations?.

These issues are briefly summarized below.

Specific functions and underlying purposes of LABs. According to the proposed rule, LABs could have such functions as recommending ways to reduce residual radioactivity that are technically achievable, not prohibitively expensive, and do not result in net harm to people or the environment; providing advice on whether proposed institutional controls are effective, enforceable, and not unduly burdensome; and advising on whether the licensee has provided sufficient financial assurance to ensure that necessary control and maintenance of the site will be carried out. Underlying LAB purposes could include, for example, improving stakeholder understanding of the decommissioning process through information exchange, empowering traditionally excluded stakeholders, and promoting decommissioning plan acceptance.

Inappropriate LAB functions might include prescribing future site ownership or enacting local land use restrictions, while inappropriate underlying purposes might include stakeholder cooptation or using LABs as substitutes for other public input.

LAB objectives. Possible LAB objectives could address, for example, the adequacy of stakeholder representation; the degree of $\mathrm{LAB}$ responsibility; the timing, form, and use of $\mathrm{LAB}$ advice; and the LAB's deliberative capability. In specifying objectives, tradeoffs may need to be dealt with, since all objectives may not be maximally achievable. In addition, the possible need for a two-step process in establishing LABs may merit consideration, especially if LABs are tailored to accommodate different licensees and affected communities, thereby enabling Commission pre-approval of a LAB, its specific set of objectives, and its proposed methods of implementation.

Implementation details. Once the need for a LAB has been identified, a plethora of implementation details must be resolved. These include, for example, how large the LAB is to be, who is to select its members, whether participants' expenses will be reimbursed and whether honoraria will be provided, how agendas are to be set, whether an outside facilitator will be used, 
and whether mediation will be sought in the face of intractable conflicts. Also included are important financial considerations such as who will pay for LAB costs and whether the LAB will have a set budget limit, as well as the issue of who makes the decision to terminate a LAB, and under what circumstances. Underlying these implementation details is the question of how responsibilities for $\mathrm{LAB}$ implementation should most appropriately be allocated -- e.g., allocation among the licensee, the NRC, an independent steering committee or other third party, and the LAB itself.

Prescriptive vs. performance-based rulemaking. A prescriptive approach to a LAB rule might help ensure that licensees would not overlook or ignore important considerations in LAB establishment and operation. However, this approach could force licensees and LABs to fit a limited number of molds. In contrast, a performance-based approach might enable licensees and affected communities to tailor LABs to their particular circumstances. To be effective, however, a performance-based approach might necessitate the use of verification and evaluation measures. Hybrids between a prescriptive and a performance-based approach are also possible. In reality, there is often no bright line between them.

LAB appropriateness and substitutability; possible impediments to participation. At some sites where a restricted use is proposed, a LAB may not be necessary because the use restriction is likely to be of short duration. Conversely, there may be some sites where a restricted use decommissioning is not contemplated but where a LAB-like body may be appropriate. In some instances, an existing organization such as a local environmental review board may be able to substitute for the LAB -- possibly in an augmented or altered form -- thereby helping to minimize the effort, expense, and potential duplication and controversy of establishing a LAB. In gauging the appropriateness of using an existing group as a LAB substitute, consideration may need to be given to the two-fold danger of distorting the LAB's mission by tying it to an existing mandate and taxing the group by asking it to assume an additional mandate. Impediments to LAB participation may include agency restrictions on employee participation and tort liability concerns, the latter stemming from fears that public employees may be held liable for wayward LAB decisions. It may be desirable to consult existing local advisory groups concerning methods to overcome these potential impediments.

Evaluating LAB effectiveness. Once established, LABs may need to be evaluated in order to improve their performance, determine if their advice has been useful to (and used by) licensees and the NRC, and refine NRC guidance concerning LABs. Possible performance criteria might include such factors as timeliness of advice, short-term time and cost efficiency, and long-term payoffs. Regardless of criteria, thought may be need to be given to who should perform evaluations, when they should be conducted, and how their results should be used. Results of $\mathrm{LAB}$ evaluations could range from "mid-course corrections" for individual LABs to a decision by the Commission to revamp, terminate, or expand the $\mathrm{LAB}$ requirement. 


\section{APPENDIX-A}

\section{NEED FOR OBTAINING TIMELY INPUT FROM AFFECTED PARTIES}

NRC's enhanced participatory rulemaking process on decommissioning identified a particular need for stakeholder participation in instances where restrictions on future uses of decommissioned sites are proposed. It also identified other mechanisms for public participation whenever a site is to be decommissioned.

The need for fuller stakeholder participation became apparent through the enhanced participatory rulemaking process used by NRC to develop the proposed rule on decommissioning. A series of public workshops was held in 1993, at an early stage of the rulemaking process. One theme coming out of these workshops was the need for increased public participation in the site decommissioning process. Another issue raised in the workshops was that the requirements of decommissioning should provide equal protection for individuals, especially rural populations and people of color, as well as protection for the environment.

NRC's stated intent in the proposed rule (Federal Register, Vol. 59, no. 161, August 22, 1994) for public involvement is two-fold. First, the Commission wants the public to be fully informed of the decommissioning actions at a particular site and to be able to participate effectively in site decommissioning decisions. Second, the NRC and the licensee should be informed of public and stakeholder views early in the process.

Section 20.1406 of the proposed rule describes general requirements for public notification and public participation in the instance of a site decommissioning. Upon receipt of a decommissioning plan, or a proposal for a restricted release of a site, or whenever the Commission deems such notice to be in the public interest, the Commission will notify state, local, and/or Native American governments in the vicinity of the site that could be affected by the decommissioning; publish a notice in the Federal Register and other appropriate media; and solicit comments from the public on the proposed decommissioning action. 
APPENDIX-A

\section{PORTIONS OF THE PROPOSED RULE PERTAINING TO LABS}

The proposed rule states that "the proposed termination of licenses and release of sites under conditions of restricted release involve issues (e.g., land restrictions) that could have unanticipated adverse effects on the local community." (p. 43214) For this reason, it is especially important that the interests of all affected parties be represented early in the planning stages of decommissioning. To this purpose, the Commission has proposed requiring the creation of SiteSpecific Advisory Boards (SSABs). In this paper, these boards are referred to as Licensee Advisory Boards (LABs), for the reasons given under the Background section below.

According to Sec. 20.1406 of the proposed rule, for those decommissioning actions where the licensee proposes restricted release of a site, the licensee would be required to convene an advisory board to obtain advice regarding the proposed decommissioning from affected parties. Section 20.1407 describes the functions a LAB should assume, what the membership of a LAB should be, and who should be responsible for establishing and supporting the LAB. It also notes the need for public access to $\mathrm{LAB}$ meetings and records.

The suggested functions of the $\mathrm{LAB}$ are discussed in Issue 1 of this paper. The suggested requirements for $\mathrm{LAB}$ membership include the following: that a $\mathrm{LAB}$ consist of approximately 10 members plus one ex officio member selected by the Commission; that a LAB represent the interests of the affected community and region (including those of the licensee; local and state governments; people who live near the site; citizen, environmental justice, and other public interest groups; and indigenous people with treaty or statutory rights that could be affected by the proposed decommissioning); and that members be nominated by organizations representing the interests of the affected community. The proposed rule requires that the licensee should be responsible for establishing the $\mathrm{LAB}$, developing appropriate operating procedures, and providing administrative and technical support to the $\mathrm{LAB}$, including access to studies and analyses that pertain to the proposed decommissioning. The proposed rule also specifies that the general public will have access to LAB meetings, including advance notification of meeting time and place, and that all records generated by the LAB will be available for public inspection.

LABs are intended to provide a mechanism for early public involvement in the development of a restricted use decommissioning plan for a site. They are meant to complement, not replace, the other public participation mechanisms noted above and in the Background section. Through LABs, licensees can become more directly involved with affected parties, interacting closely with them and hearing their concerns. 


\section{APPENDIX-A}

\section{BACKGROUND}

\section{Existing Requirements: Public Participation and Environmental Justice}

Current regulations allow for public participation in decommissioning through public access to relevant documents, hearings and other meetings open to the public, and the solicitation of oral or written comments. At present, in addition to federal "sunshine" laws, there are two regulations potentially relevant to public participation in a site decommissioning: 10 CFR Parts 2 and 51. As discussed further below, the NRC is considering substantially expanding upon these avenues for public participation in site decommissioning. In addition, the NRC, together with other federal agencies, is addressing the mandate issued by President Clinton to reflect environmental justice considerations in its decisions.

Regulatory Procedures . 10 CFR Part 2 includes requirements for the pre-hearings and hearings held by Atomic Safety and Licensing Boards on nuclear facility license applications, amendments, or renewals, or on applications for construction permits. General procedures that apply to licensing hearings for nuclear reactors are contained in Subpart G of Part 2. Hearing procedures for nuclear materials facilities are described in Subpart $L$. The requirements in Part 2 also cover procedures for issuing, amending, transferring, or renewing licenses, enforcement actions, and rulemakings. Hearings are open to the public, but participation by a person who is not a party to the action is left to the discretion of the hearing's presiding officer. In particular, the regulation provides for "limited appearance" participation in hearings: an oral or written statement may be given "within such limits and on such conditions as may be fixed by the presiding officer," but such a person "may not otherwise participate in the proceeding." Of particular importance for public involvement in 10 CFR Part 2 are the procedures for submitting petitions for regulatory action under $\$ 2.206$ and rulemaking petitions under $\$ 2.802$.

The NRC terminates about 300 licenses each year, most of which are routine and do not involve significant remediation. A small fraction of these sites require special attention to resolve decommissioning policy and regulatory issues. The public has expressed interest in the decommissioning of a number of licensed sites. The amount of effort devoted by the NRC to public information and involvement in licensing actions varies from site to site based on the amount of public concern and the complexity of the action required. For example, if a local community expressed concerns associated with licensing actions, the NRC considers and has often held a public meeting to explain NRC's role, the characteristics of the site, and the licensee's planned decommissioning approach and alternatives. At sites where there is concern expressed by the public and elected officials, the staff has invested a substantial effort in meeting periodically with officials and members of the public.

Based on experience in overseeing decommissioning activities at a number of sites, NRC has identified goals for improving public involvement in the ongoing licensing of decommissioning actions. These include: establishing and building trust between citizens, agencies and licensees: enhancing the openness of the process for public observation, information and involvements 


\section{APPENDIX-A}

answering questions from the public in a timely manner; and encouraging licensee openness and responsiveness to legitimate public concerns, including presentation of a decommissioning program at the outset. Effective communication with the public prior to initiation of decommissioning or the NRC's approval of the decommissioning plan could save many hours later in answering questions or responding to allegations. In some cases, NRC has routinely met with designated representatives of different interests at decommissioning sites to exchange information and in explore public concerns.

Environmental Review. The National Environmental Policy Act (NEPA) requires federal agencies to review the environmental consequences of any major proposed federal actions, including regulatory actions. NRC requirements that implement NEPA are described in 10 CFR Part 51. NRC typically approves decommissioning plans for nuclear facilities through decommissioning orders (nuclear reactors) or license amendments (nuclear materials facilities). These actions are supported by Environmental Assessments (EAs) or Environmental Impact Statements (EISs), in addition to the draft generic EIS published August 1994 in support of the NRC's proposed rulemaking on radiological criteria for decommissioning and the generic EIS that supported the 1988 rulemaking that established general requirements for decommissioning licensed nuclear facilities. Part 51 also contains categorical exclusions for actions involving negligible impacts that were previously evaluated in developing the requirements in Part 51.

If an EIS is contemplated, the NRC must publish a notice of intent in the Federal Register. The notice announces the beginning of the "scoping" process, in which NRC solicits public comment on the impacts and alternatives to be considered in developing the EIS. This notice must include a description of the proposed EIS scoping process; the role of participants in the scoping process; whether written comments will be accepted, and if so, the deadline for comments; whether, when, and where a public scoping meeting will be held; and who within NRC to contact for more information.

Following the scoping process for an EIS, the NRC prepares and issues a draft EIS for public comment. Following the review and comment period, NRC revises the EIS as appropriate and publishes a final EIS that identifies a preferred alternative and includes comments received on the draft EIS and responses to those comments. In the case of decommissioning, the preferred alternative would typically consist of a specific approach for completing the removal and disposal of residual radioactive material. Availability of the draft and Final EISs is published in the Federal Register. At the conclusion of the EIS process, NRC completes a public record of decision which briefly summarizes the results of the EIS along with any license conditions or monitoring requirements adopted in connection with mitigation measures. The adequacy of the EIS is also reviewed by the Environmental Protection Agency.

Environmental Justice. Executive Order 12898, issued by President Clinton on February 11, 1994, provides for federal actions to address environmental justice issues in minority and lowincome populations. According to this order, each federal agency is to make environmental justice a part of its mission by identifying and addressing, as appropriate, disproportionately high 


\section{APPENDIX-A}

and adverse human health or environmental effects of its programs, policies, and activities on minority and low-income populations.

\section{Site-Specific Advisory Groups: A Possible Model?}

Federal agencies such as the Department of Defense (DOD) and the Department of Energy (DOE) have established advisory boards in order to incorporate stakeholder concerns. Many but by no means all of these boards had their inception following the February 1993 report of the Federal Facilities Environmental Restoration (FFER) Dialogue Committee convened by U.S. Environmental Protection Agency, which included 40 representatives of state and federal agencies and interest groups from around the nation. In this report, the FFER Dialogue Committee recommended that "Site-Specific Advisory Boards" (SSABs) be established as one means of attaining sustained involvement of stakeholders in plans and decisions concerning the clean-up of federal sites.

As popularized by the FFER Dialogue Committee, the term "site-specific advisory board" has come to imply an advisory board to a federal facility. It has also come to imply a standing board of indefinite duration that would advise on a range of environmental restoration and waste management issues. In both these respects, advisory boards to NRC licensees preparing decommissioning plans would differ: they would usually be advisory to a private, regulated organization on issues concerning private property, not to a federal agency on issues concerning government-owned land; and they would be of limited duration and scope. For these reasons, the term "Licensee Advisory Board" (LAB) will be used as a placeholder in this issues paper, in lieu of the term "SSAB." Selecting a name for the group should be one of the items discussed at the workshop. Nevertheless, the prior experience of federal facilities and other organizations with advisory groups can provide useful background in considering how LABs should be formed.

DOE. In the months following the FFER Dialogue Committee's report, DOE endorsed the concept of SSABs and began the process of establishing SSABs at several sites, including, e.g., Hanford, Rocky Flats, Savannah River, and Oak Ridge Reservation. While a few are now established, most are too new to be assessed.

The concept of an SSAB is not altogether new, however. Within the DOE complex, this concept has been employed in one form or another since the early 1980s. The types of groups established can be divided into three categories: some have been formed by and report to DOE or a DOE contractor; some are DOE- or contractor-formed but operate independently; some are formed and funded by states.

Within the first category, members usually serve at the appointing organization's pleasure. The group's agendas tend to be externally determined. Typically, these groups are charged with reviewing site activities, providing comments on an assigned problem, and producing reports. When their duties are completed, they may be disbanded. 
Groups in the second category differ from those in the first in three ways. First, they are independently run and have their own support personnel. They convene meetings on topics of their own choosing and are provided with a budget which may be used to obtain expert testimony, prepare independent analyses, and conduct hearings. Second, they may issue their own reports directly to the public. Finally, they tend to focus upon "legacy" issues at their respective sites; e.g., worker and public health and safety issues, waste management planning, and investigation of accidental releases of radiation.

Advisory groups in the last category operate as independent 'watchdogs.' Typically, members are appointed by states or through some independent mechanism and view themselves as answerable to outside constituencies. These groups also tend to have 'lay' rather than 'expert' appointees. They may be granted DOE funds to conduct independent studies, and they focus on issues ranging from health and environment to economic development and future land use.

DOD. DOD experience with site-specific advisory groups is of somewhat more recent vintage. For the purposes of this discussion, those most relevant are Restoration Advisory Boards (RABs). RABs are being formed at active and closing installations where there are hazardous waste cleanup programs. A RAB's purpose is to provide an open forum for information exchange between the installation, federal and state regulatory agencies, and the community. RABs thus afford communities a voice in the cleanup process.

RABs are formed in one of two ways. First, at DOD installations that already have a Technical Review Committee (a committee with external representation to review and comment on clean-up activities), the committee is expanded to include additional representation. Second, at DOD sites without Technical Review Committees, a RAB may be formed when at least 50 citizens request it; federal, state or local officials petition for it; or an installation commander determines that there is a need for one.

RABs are co-chaired by an installation representative and a community member. RAB membership includes state and local officials, officials with the regional office of the U.S. Environmental Protection Agency (EPA), installation personnel with relevant skills (e.g., medical or remediation experts), and representatives of the community. The RAB membership selection process is highly formalized. Typically, the installation commander, in consultation with EPA and state officials, identifies relevant community interests. A selection panel is then formed to identify potential candidates.

RABs are designed to provide input directly to installation officials, who must document both their efforts to solicit input and steps taken to implement it. At bases that are scheduled to close, RABs may also provide input through another vehicle called the "Community Reuse Committee." The latter is charged with developing site reuse options, parceling-off installation properties, and preparing zoning rules. 


\section{APPENDIX-A}

Local Emergency Planning Committees (LEPCs). LEPCs were formed as a result of the emergency preparedness and community right-to-know provisions in Title III of the 1986 Superfund Amendments and Reauthorization Act (SARA). Under those provisions, all states are required to divide up their jurisdictions into "emergency planning districts."

The purpose of LEPCs is to enhance the ability of state and local governments to respond to emergencies involving the accidental release of toxic substances from factories, farms, warehouses, or other industrial or commercial facilities. LEPCs oversee development of chemical emergency plans, handle information requests from the public, evaluate local resources for responding to emergencies, and develop risk management and risk communication programs. They also facilitate the implementation of SARA provisions designed to increase the public's access to information about the presence of hazardous chemicals in their communities, and about releases of chemicals into the environment.

Typically, LEPC membership includes officials whose work is involved with emergency management (e.g., officials in law enforcement, fire protection, civil defense, public health, environmental protection, and transportation), as well as representatives of community groups. While the task of identifying members is facilitated by the clearly defined geographic boundaries of the district, in some states the districts are very large and may even encompass the whole state. Furthermore, it can be difficult to determine which types of officials are most important to chemical emergency management issues. It can also be difficult to find active community representatives, due to the paucity of organized groups in some rural areas and, at times, to apathy about chemical hazards.

Citizens' advisory boards in private industry. Other, non-mandated forms of citizens' advisory groups also have been adopted over the last decade or so. This has occurred as industries seek to broaden their responsiveness to risk issues by developing mechanisms for stakeholder involvement.

One example can be seen in the chemical industry, where various citizens' groups have been convened under the appellation, Citizens' Advisory Committees (CACs). CACs have taken various forms. Most commonly, they are committees of citizens who live in communities that are directly affected by the operations of a chemical plant. The establishment of CACs is driven by the chemical industry's desire to become more receptive to public input concerning its operations, including potential risks posed to communities. In this role, a CAC provides a corporation with a means of demonstrating social accountability and sensitivity to community welfare. In some rare instances, CACs have been elevated to the stature of an informal citizens' board of directors and report directly to a corporation's board of directors. To date, little formal evaluation of chemical industry CACs has taken place. Consequently, it is not yet altogether clear what effect such groups are having on chemical industry operations and risk management.

A second example comes from the electric utility industry. Some recent research has suggested that exposure to electromagnetic fields (EMFs) may lead to adverse health effects, especially in 


\section{APPENDIX-A}

sensitive populations. Although no firm scientific conclusions have been drawn yet about the relationship between EMF exposure and health effects, some citizens have voiced concerns about the safety of electric power transmission and distribution. In some instances, this concern has prompted litigation. As a result, some utilities have convened stakeholder groups. In some cases, groups have been facilitated by outside consultants who then provide feedback to the utility; in other cases, a utility representative either is part of the group or attends meetings as an observer. Typically, groups are given background information on a number of topics ranging from the basics of power generation to epidemiology but have no specific charge; indeed, their function may be oriented toward public relations and assuaging citizen concerns through increased information.

\section{Lessons for $L A B S$}

Because of their newness, the effectiveness of the advisory groups described above cannot be definitively evaluated. Nevertheless, based upon information available so far (see, e.g., English, Gibson, Feldman, and Tonn, Stakeholder Involvement: Open Processes for Reaching Decisions about the Future Uses of Contaminated Sites, University of Tennessee Waste Management Research and Education Institute, September 1993; Scrimgeour and Hanson, Advisory Groups in the U.S. Department of Energy Environmental Cleanup Process: A Review and Analysis, Colorado Center For Environmental Management, April 1993), several general lessons of potential importance to LABs can be identified:

- Groups whose members are chosen by and serve at the pleasure of the organization they are to advise may be perceived as being controlled by that organization. This is especially the case if the group does not have funds available for independent analysis. In contrast, a formalized, semi-independent member selection process and the availability of funds for consultants may help avoid the appearance of control.

- Misunderstanding and ill will can arise if there is not a clear agreement at the outset on the group's role (e.g., information exchange v. decision making).

- The product of a group's deliberations is more likely to be influential if the expertise of members matches well with a given problem.

- Efforts to bring an advisory group in direct contact with a facility's operation (including, if necessary, security clearances and access to confidential information) can improve the group members' perceptions of the organization they are supposed to advise.

- Facilitators may contribute to the effectiveness of group analysis and decision making, by structuring discussions and helping to ensure that all viewpoints are given the opportunity to be voiced. 


\section{APPENDIX-A}

- If a group's advice is not made public by the organization soliciting the advice, the organization may be seen as attempting to downplay that advice.

Given the potential parallels between LABs and some of the groups discussed above, it may be useful for a licensee to seek out relevant groups within the nearby geographic area. By consulting with them, the licensee and the LAB may be able to learn from the other groups' experiences.

\section{Number and Types of NRC Licensees}

There currently are about 22,000 licensed nuclear facilities in the United States. Licensees include all civilian nuclear facilities -- e.g., utilities with nuclear power plants, nuclear fuel fabricators, universities and medical institutions that use radioactive materials, radioactive source manufacturers, and companies that use radioisotopes for industrial purposes. Not included are defense nuclear facilities such as those of the U.S. Department of Energy, which are not regulated by the NRC.

Of the 22,000 licensees, about 7,000 are licensed directly by the NRC. The remainder are licensed by Agreement States, through agreements between individual states and the NRC under Section 274 of the Atomic Energy Act. The extent to which NRC's proposed rule amending its regulations regarding the decommissioning of licensed facilities would apply to Agreement States is being considered separately. In addition, the proposed rule would not apply to the disposal of uranium mill tailings, low-level radioactive waste, or high-level radioactive waste, which have been addressed in separate regulatory actions. It would, however, apply to ancillary support facilities at the disposal sites.

The NRC licensees can be divided into two categories: non-fuel cycle facilities, or "materials licensees"; and fuel cycle facilities. About 75 percent of NRC's 7,000 materials licensees use either sealed radioactive sources or small amounts of short-lived materials. Typically, these facilities have little or no radioactive contamination, and decommissioning is simple. The remaining 25 percent of materials licensees could pose more difficulties. Certain types of facilities (e.g., radioactive source manufacturers, radiopharmaceutical producers, and radioactive ore processors) could have substantial radioactive contamination as a result of their operations, requiring decontamination to acceptable levels before their licenses can be terminated.

The number of NRC licensees in the second category, nuclear fuel cycle facilities, is far smaller, but virtually all will require significant remediation as part of decommissioning. The nuclear fuel cycle facilities which will require decommissioning include approximately 100 nuclear power plants (at 70 sites), 50 non-power (e.g., research) reactors, 10 major fuel fabrication and uranium hexafluoride production plants, 50 uranium mills, and 10 independent spent fuel storage facilities.

Several hundred NRC licenses are currently terminated each year. Most cover limited operations that produce little or no radioactive contamination; a few present complex decommissioning 
problems. As the nuclear industry matures, however, it is expected that more and more of the larger nuclear facilities that have been operating for several decades will reach the end of their useful lives and have to be decommissioned. (For example, about three dozen nuclear power reactors now operating will shut down over the next 20 years unless their licenses are renewed.)

In March 1990, the NRC put a plan in place to effect the decommissioning of about 50 sites which require special NRC oversight because they have been improperly decommissioned in the past, or because their decommissioning has been protracted. About 50 sites are being handled under this plan, called the Site Decommissioning Management Plan (SDMP). These sites vary in size, degree of hazard, degree of decontamination, and involvement of a licensee. Many involve active licenses, but some involve formerly licensed sites or sites where the responsible party is unable or unwilling to perform cleanup. It is expected that, if a SDMP site involves a proposed restricted release, the LAB requirement would apply under the proposed rule.

\section{Applicability of $L A B$ requirement}

In the proposed rule, the Commission proposes that the requirement of a LAB apply only to licensees that intend to include restrictions on future uses of their sites as part of their decommissioning plans. For the many licensees that propose to meet the conditions for unrestricted site use following license termination, the Commission does not believe that LABs should be required, although some licensees might voluntarily decide to adopt the LAB model for their own purposes.

When a restricted use decommissioning plan is being developed, the LAB will serve as a means of getting the sustained, thoughtful input of affected parties on the viability and acceptability of alternatives being considered for the plan. Furthermore, the involvement of affected parties will help to ensure the implementation of aspects of the plan that rely on authorities external to the licensee (e.g., local or state land use controls), and it will help to establish a basis for future resolution of issues that may occur after the decommissioning plan is in place.

The Commission has recognized, however, that some exemptions to the general requirement of LABs in instances of restricted use decommissioning may be appropriate. Conversely, there may be some circumstances where a LAB-type body would be appropriate, even if not normally required. This issue is discussed further in this paper. (See Issue 5.) 


\section{APPENDIX-A}

\section{ISSUES FOR DISCUSSION}

As noted above (see "Portions of the Proposed Rule Pertaining to LABs"), the Commission has proposed the establishment of LABs in instances of restricted use decommissioning plans and has suggested how LABs might be set up and what functions they might perform. The Commission has done so because it is committed to the idea that sustained, small-group advice from representatives of affected interests should be sought whenever a licensee intends to include restricted uses as part of a decommissioning plan.

It should be emphasized, however, that the Commission is not yet committed to a particular "formula" for LABs. In other words, the Commission is not yet committed to the details concerning LABs set forth in the proposed rule. Furthermore, it recognizes that the proposed rule raises but does not answer several questions concerning LABs. As the proposed rule notes (p. 43223), the Commission is seeking comments and suggestions about how the "licensee advisory board" concept should be implemented.

With respect to LABs, the central question before the Commission is:

"How can a licensee advisory board or its equivalent optimally participate in the development of a restricted use decommissioning plan?"

This question can be broken out into the six issues addressed below. Each issue begins with a general query. Following general discussion, a series of sub-issues explore specific aspects of each major issue. Finally, a set of questions are posed to help spur ideas for further discussion.

The issues, sub-issues, and questions presented below, together with other relevant and substantial issues identified by interested parties, will serve as the basis for discussion at a workshop to be held in December 1994. At the workshop, participants will be asked to give both their views and the reasoning behind them. The workshop discussions will be used by NRC staff in its consideration of alternative strategies for implementing the LAB concept. 
Issue 1. What specific functions and underlying purposes should a LAB serve?

\section{Discussion:}

In its proposed rule, the Commission has identified three functions for LABs. LABs are to provide recommendations to the licensee on:

(1) whether there are ways to reduce residual radioactivity which are technically achievable, not prohibitively expensive, and will not result in net public or environmental harm;

(2) whether institutional controls proposed by the licensee will provide reasonable assurance that the TEDE from residual radioactivity distinguishable from background to the average member of the critical group will not exceed 15 mrem per year, will be enforceable, and will not impose undue burdens on the local community or other affected parties; and,

(3) whether the licensee has provided sufficient financial assurance to enable an independent third party to assume and carry out responsibilities for any necessary control and maintenance of the site.

(For the full text of these recommended functions, see the proposed rule, p. 43222.)

In addition, LABs might perform other specific functions. For example, they might advise licensees on mechanisms for public input concerning the development of the decommissioning plan, beyond public involvement required by NRC rule. In addition, they might provide advice to licensees on public input that may be needed later, at key points in the implementation of the decommissioning plans. Furthermore, they might provide an opportunity for airing environmental justice issues that otherwise might go unacknowledged.

In performing its functions at a given site, a LAB could serve one or more underlying purposes. For example, it could (1) improve understanding of the decommissioning process and of the consequences of the decommissioning plan through a sustained, in-depth information exchange with representatives of key stakeholder interests; (2) improve the quality of the decommissioning plan by bringing to bear both the knowledge and the values of LAB members; (3) promote widespread acceptance and ownership of the decommissioning plan by having it developed in a participatory fashion; and (4) promote the ideals of environmental justice by empowering stakeholders that historically have lacked political and economic clout.

\section{Sub-issues:}

Off-limits functions. Some functions might be explicitly designated as "off-limits" for LABs: for example, prescribing who subsequent site owners should be, requiring the enactment of local land use restrictions, or otherwise infringing on various parties' authority and responsibility to implement the decommissioning plan. 


\section{APPENDIX-A}

Inappropriate underlying purposes. There may also be inappropriate underlying purposes for LABs. Examples of inappropriate underlying purposes include co-optation of key stakeholders, use of a LAB as a substitute for other meaningful public input, or use of a LAB as "windowdressing" while ignoring its advice could all be inappropriate.

\section{Questions:}

1. A LAB's ability to perform various functions will depend upon how it is set up (see Issues 2 and 3). Putting ability temporarily aside, how desirable are the specific functions that the Commission has proposed for LABs?

2. Are there other specific functions that a $\mathrm{LAB}$ should be required or requested to perform?

3. To what extent could a LAB deal with environmental justice issues?

4. Are there functions that are clearly inappropriate for LABs? If so, are these functions inappropriate because of their nature, or because other organizations already perform them?

5. As with functions, a LAB's ability to serve various underlying purposes will depend upon how it is designed: e.g., who its members are and how they are chosen. These design considerations will be discussed under Issues 2 and 3. Putting design considerations temporarily aside, what are the desirable underlying purposes for LABs?

6. Are there underlying purposes that are clearly inappropriate for LABs?

7. Given their specific functions and underlying purposes, what should "licensee advisory boards" be called? What are the implications of alternative names? 
Issue 2. What are the general objectives of a $\mathrm{LAB}$, and how can they be achieved?

\section{Discussion:}

Various sections of the proposed rule note that (1) local parties should have early and substantive input into the decommissioning process, with $\mathrm{LAB}$ activities occurring during development of the decommissioning plan rather than after the licensee has spent considerable time and effort on a decommissioning proposal; and (2) the LAB's involvement in the development of the decommissioning plan should provide an information exchange between the licensee and the public.

To achieve these goals, guidance may be needed to aid the licensee in structuring the LAB and the nature and content of its deliberations. Sub-issues critical to achieving a representative process that provides timely, useful input to the licensee's decommissioning plans are discussed below.

\section{Sub-issues:}

Adequacy of stakeholder representation. It is the intent of the proposed rule to achieve broad stakeholder representation of interests affected by the site to be decommissioned. This poses the dual problem of deciding which interests merit representation and who can speak for whom.

The licensee has an obvious interest, if only because of the costs and possible future liability involved with decommissioning. In some cases, the licensee may plan to turn the decommissioned site over to another party for management or development. If identified during development of the decommissioning plan, this party's interests may also warrant representation on the LAB.

State and local officials will need to be represented, especially if boards, commissions, or other groups have responsibility for reviewing aspects of a licensee's site decommissioning plan. In addition, for some sites, Native American interests will need to be represented.

People living near the site will need to be represented. They could potentially experience direct health and safety effects (as well as economic and social effects) from residual radioactivity, interim storage of radioactive waste, or a decommissioning plan that entails an amended or modified mode of operation of the licensed facility.

Representation of minority and low-income groups that either have been or could be adversely affected by the site will also be important. These groups may or may not constitute a majority of the population living near the site. Either way, their interests should not be assumed to be the same as those of others living in the site's vicinity. 


\section{APPENDIX-A}

Given the array of interests that may need representation, one approach could be to simply appoint opinion leaders, including elected or administrative officials. While these people may be readily identified, a potential disadvantage of this approach is that they may not represent all of the affected interests at a particular site. For example, some interests (e.g., ecological interests) are associated with the welfare and well-being of the community and region at large, rather than being linked to specific individuals. To correct for this, opinion surveys could be used to identify such broad community interests, and may lead to the identification of particular individuals or groups able to represent those interests.

An additional problem arises if there are so many interests requiring representation that the size of the LAB would be cumbersome. This problem is addressed under Issue 3 .

Degree of $\mathrm{LAB}$ responsibility. For a $\mathrm{LAB}$ to function effectively, its degree of responsibility needs to be made clear. One option is for the $\mathrm{LAB}$ as a whole to be charged with deciding aspects of the licensee's proposed decommissioning plan. This would invest the LAB with authority to help shape the plan, but it would also burden the LAB with greater accountability, both to the licensee and, possibly, to other constituencies. A second option is for the LAB to simply offer recommendations. This reduces the LAB's responsibility, but it also decreases its influence. As a third option, a hybrid is possible: the LAB could make general recommendations about the plan as a whole, but representatives of organizations with authority over parts of the plan could specify the acceptability of those parts.

Form of LAB advice. The LAB could provide its advice as either a group or a set of individuals. If it is to provide advice as a group, then its "decision rules" must be made clear. This is important for several reasons. First, the decision making process depends in part on the charge to the LAB. If a discrete judgment is sought, a voting procedure might be appropriate. However, if the charge is to conduct open-ended discussions, then a consensus-type procedure might be more appropriate. Second, the process depends upon the size of the LAB. Consensus is much more difficult to achieve with larger groups. Third, details about how frequently the $\mathrm{LAB}$ is to meet and for what length of time affect the $\mathrm{LAB}$ decision making process. More time is needed when seeking consensus; less time for majority rule methods. Finally, the decision process directly affects the type of advice given by the LAB. For example, while majority vote procedures might be more time-efficient, such advice will likely produce minority opinions. Consensus usually takes more time but may produce more unified advice.

Use of $\mathrm{LAB}$ advice. At a minimum, the results of $\mathrm{LAB}$ deliberations on the proposed plan should be used by the licensee informally, to develop and refine the plan. Results could simply be communicated to the licensee as a set of written or oral comments (from the entire LAB, from subgroups, or from individual members). One option is to regard such comments as advisory only to the licensee. This would provide the licensee with wide latitude and the plan would probably be developed more quickly, but it reduces the likelihood that stakeholder interests would be reflected in the plan. Alternatively, as suggested in the proposed rule (p. 43222), the licensee could be required to include with the proposed decommissioning plan the LAB recommendations 
and the disposition of those recommendations. In reaching its decision on the proposed plan, the Commission might also be required to comment on $\mathrm{LAB}$ recommendations that it has decided not to follow. This has the advantage of demonstrating that $\mathrm{LAB}$ recommendations have been given adequate consideration by the Commission. It does mean, however, that recommendations would need to be in writing. Furthermore, if a recommendation is made by an individual LAB member rather than by the group as a whole, the licensee and the NRC may be unsure of the extent to which the recommendation is supported by other LAB members (although having licensee and NRC representatives at $\mathrm{LAB}$ meetings would help to address this concern).

Problem characterization. To perform its functions, the LAB will need to characterize the problem before it. Doing so may require access to studies and analyses pertinent to the proposed decommissioning. The licensee may be the main source of information. Other sources could include state or local agencies and other groups with particular interests, such as environmental groups.

Analyses received by the LAB may differ in many respects. Some may be more detailed than others. All are likely to reflect the goals and methodological preferences of their authors. The LAB will need to assess the quality of these analyses. Guidelines for assessment could include criteria such as adequate explanation of technical language, specification of the full range of consequences for various decommissioning scenarios or plans specified, indication of the reliability of technical analyses, and identification of potential sources of bias.

Deliberative capability. Especially if the LAB is to provide group advice rather than simply individual opinions, its members need to deliberate together effectively. Deliberation involves a weighing of facts, values, and arguments in reaching conclusions. There are two general approaches. The first is informal: the group thinks through a topic or problem intuitively, using whatever means are readily available. The second is more formal: the group employs structured tools such as decision analysis and Delphi techniques. Informal deliberation has the advantage of requiring little or no outside expertise or technical support. However, it can result in the omission of important factors. Formal analysis helps ensure completeness and may make clearer distinctions between facts and values. However, it requires more external support and may be inappropriate for some problems, particularly those that do not lend themselves to quantification (e.g., the assessment of social impacts of decommissioning).

Apart from the analytic methods employed, the quality of the LAB's deliberations will be affected by such factors as (1) the ability of individual members to understand the decommissioning plan and its related analyses, and (2) the ability of individual members to recognize and tease out issues that might go unnoticed. A LAB composed solely or primarily of people with expertise on some aspect of the decommissioning plan may succeed on the first score but fail on the second. At issue is how much technical expertise LAB members should have, individually and collectively, and whether technical expertise can be incorporated by means other than membership on the LAB. 


\section{APPENDIX-A}

The deliberative capability of a group may be enhanced if "side conversations" between two or more members outside the group setting are discouraged. This may be especially important if group consensus is sought: by exchanging views and information as a group, the LAB may be more likely to develop a shared group viewpoint. However, this approach may be inefficient on highly technical issues, or it may lead to stalemates on volatile issues. In such cases, the LAB may be better able to deliberate in subgroups (possibly composed not only of LAB members but also of other experts or interest representatives).

Timeliness of setting up the $L A B$ and seeking its advice. One intent of the LAB provision is to provide a mechanism for early stakeholder involvement. To this purpose, the LAB could be created and its advice sought when the licensee has just begun to weigh possible decommissioning options. This might complicate $\mathrm{LAB} /$ licensee interactions, however, particularly if the licensee has not yet formulated a clear set of options. Waiting to set up the LAB until the licensee has a preliminary sketch of the decommissioning plan would provide the LAB with more distinct issues to evaluate. The further along the decommissioning plan is, however, the more likely it is that new options will not be readily entertained. As an intermediate approach, the LAB could be set up very early in the process of plan development, but with the understanding that its first tasks would be to refine its operating procedures and develop its background understanding of the site and related issues, with options analysis as a future task.

Tradeoffs among objectives. While maximally achieving such objectives as broad stakeholder representation, timely establishment of the $\mathrm{LAB}$, and optimum deliberative capability would be desirable, it may not be possible. For example, ensuring that the LAB is fully representative of stakeholder interests may make it so large as to impair its deliberative capability. To address the problem of tradeoffs among objectives, the licensee and/or NRC could consider ranking objectives according to the central concerns associated with the particular site involved. Alternatively, the Commission could decide a priori to emphasize one or more objectives, while giving the licensee discretion in the degree to which others are met.

Possible need for a two-step process in establishing a LAB. As suggested in the proposed rule (p. 43222), a two-step process for establishing a LAB may be appropriate. When the licensee submits notification of intent to have a restricted use decommissioning, a plan for establishing and operating a $\mathrm{LAB}$ is also submitted. Following Commission approval, the licensee implements the $\mathrm{LAB}$ and develops the decommissioning plan. This two-step process could reduce the likelihood that the licensee's approach to its LAB would be found deficient after a decommissioning plan had been developed and submitted to the Commission. Pre-approval of a LAB plan may also help resolve issues about tradeoffs among objectives early on, before the LAB has been convened.

\section{Questions:}

1. How should the range of interests in a prospective site decommissioning plan be determined? Should a distinction be drawn between legitimate and non-legitimate interests? Who should 
identify the relevant interests -- e.g., could a "skeleton" LAB be set up that would then identify other interests to be included? Are there interests for which no representative can be found, or for which only the community at large can serve as a representative?

2. What type of representation on a LAB is needed to deal with the issue of environmental justice?

3. To what extent should the licensee empower the LAB to develop aspects of the proposed decommissioning plan?

4. Are there certain key issues on which the LAB should be asked to reach consensus, or, if consensus can't be reached, to vote?

5. Should members be accountable to their constituencies -- in other words, should they serve as "delegates"? Or should they give advice only according to their own thinking?

6. To what extent should LAB members be chosen for their prior expertise in or knowledge about an aspect of the proposed decommissioning plan? Should the LAB, collectively or individually, be given formal training or assistance in understanding complex information and analyses?

7. The question of funding independent consultants to the $L A B$ will be discussed under Issue 3 . In principle, should the $\mathrm{LAB}$ be afforded the means to make an independent assessment of the adequacy of technical analyses? Are there specific factors, information, or analytic techniques that should not be used in developing advice? -- For example, should the LAB not attempt to develop benefit/cost ratios for various decommissioning options?

8. At what point should the LAB be set up?

9. To whom should the LAB give its advice? To the licensee only, to the NRC only, to the licensee and the NRC, or possibly to others? How should the LAB's advice be treated in considering the decommissioning plan?

10. What LAB objectives are most important? Who should rank them? How should possible tradeoffs among LAB objectives be addressed, and by whom?

11. Should the licensee be required to submit a LAB plan for the Commission's approval, before the $\mathrm{LAB}$ is established? If so, at what point should the plan be submitted? 


\section{APPENDIX-A}

\section{Issue 3. What implementation details need to be considered when establishing a LAB?}

\section{Discussion:}

Once the need for a LAB is identified, someone must take responsibility for its establishment, operation, and termination. Success with implementation details will allow the LAB to focus on its main objective: providing sound advice to the licensee. Failure can lead to organizational problems that can escalate to such a degree that they jeopardize the entire advisory process. Inattention to implementation details may also call into question the licensee's and/or NRC's commitment to the LAB process.

It is assumed here that the licensee will be responsible for implementation. However, the NRC and others could share responsibility. Thus, one sub-issue, discussed at the conclusion of this section, is who should be responsible for implementation.

Sub-issues:

Initiating a LAB. Issues associated with initiating a $\mathrm{LAB}$ include determining when to form the $\mathrm{LAB}$; announcing its formation (e.g., using newspaper ads, officially informing public officials); inviting stakeholders to join the $\mathrm{LAB}$; deciding whether to reimburse expenses and pay LAB members honoraria for their participation; and determining whether LAB members need to make any commitments, written or otherwise, to the LAB process and/or the licensee as a condition for LAB membership (e.g., commitments not to disclose confidential business information).

Perhaps the greatest challenge in terms of initiation is to ensure that the LAB is large enough to permit representation of all relevant stakeholder interests, yet small enough to permit meaningful interaction and deliberation. While there is no "formula" for determining optimum size, as a general rule a group larger than, say, 10 to 15 members is likely to find informal interaction difficult. Considerable thought needs to be given to balancing the need for sufficient representation of a number of relevant interests with the advantage of having a small core of committed, competent participants able to devote time and energy to discussion of decommissioning issues.

To address the problem of size, it may be necessary to consider, first, whether some interests are more crucial than others; second, whether some members of the LAB can represent more than one set of interests; and third, whether there are ways to informally involve peripherally affected parties without expanding the size of the LAB (e.g., through periodic workshops held by the $\mathrm{LAB}$ where other participants are invited, or by inviting representatives of certain interests to attend $\mathrm{LAB}$ meetings when topics particularly germane to them are to be addressed).

During the initiation stage, rules for participation may be needed: e.g., who has the final say on specific appointments to the LAB once stakeholder groups have been identified (the stakeholder groups, the licensee, the NRC, an independent third party?); whether alternates can serve in the 
absence of appointed members; and how appointed LAB members will be replaced if they terminate their LAB membership once the process has begun. Some of these "groundrules" may need to be specified by the licensee or by an independent third party; others can be developed by the $\mathrm{LAB}$ once it has been established.

It may be appropriate to reimburse the LAB members for travel and other expenses (e.g., child care) incurred by them as a result of their participation. In addition, honoraria may be appropriate, especially if participation by some members would be precluded because it would entail taking time from their paid jobs. In deciding whether or not to offer honoraria, the needs of the LAB may be an important factor. If it is thought that representation of certain categories of stakeholders on a LAB is absolutely necessary, then honoraria might be appropriate.

However, honoraria may contribute to the impression that participants are being "bought off." In this case, covering only the participants' expenses might be preferable.

Operational issues. Several issues must be addressed with respect to the actual operation of the LAB. These include such issues as when and how often to hold meetings, how agendas should be set, and whether the LAB meetings should be public or private (or a mix, depending on the topic under discussion). Decisions also need to made about how the LAB will be led (e.g., by a chair appointed by the licensee or by LAB members); whether the LAB should have an outside facilitator to help structure discussions and lead brainstorming sessions, and if so, how one should be selected; and, as discussed under Issue 2, how decisions on group advice should be made (e.g., by consensus, by majority vote, etc.) and advice communicated.

Administrative and technical support. The LAB may require administrative support from the licensee, including meeting space, office supplies, and communications support (e.g., phone, fax, wordprocessing). To compile reports and prepare correspondence, the LAB may require secretarial support. The LAB may also require financial assistance to acquire technical support, both internal to the LAB (e.g., someone to collect reports and maintain an information data base) and external to the LAB (e.g., for outside consultants on groundwater testing, the human health effects of radiation, etc.).

Without some minimal level of support, the LAB's ability to effectively deliberate and provide timely advice to the licensee may be compromised. However, due to time and cost constraints, the LAB probably should not seek to (or be expected to) replicate credible scientific and technical studies conducted by the licensee and others. A strong working relationship between the licensee and the LAB will probably be needed to ensure that administrative and technical support is timely and cost-effective.

Cost drivers. The experience of LAB-type bodies (see Background section) suggest that there are five basic factors affecting advisory board costs. The larger an advisory board, the more frequently it meets, the greater the distances involved in convening members (or support personnel, witnesses, and consultants), the more extensive the clerical tasks required, and the longer the board's duration, the more expensive it will be to operate. Actual costs of a LAB are 


\section{APPENDIX-A}

difficult to estimate, both because existing advisory boards have had widely varying experiences regarding each of these factors, and because some agencies absorb the clerical, travel, and other costs associated with advisory board operation under larger budget categories (e.g., community relations, public information).

The licensee's ability and willingness to bear LAB costs may be influenced by many factors (e.g., the licensee's financial health, the perceived benefits of the LAB to the licensee's goal of decommissioning a facility). In some instances, it may be very important to the licensee to anticipate and control LAB costs. Means of controlling LAB costs could include, for example: setting a fixed "per diem" to cover member expenses, with additional expenses reimbursable on a case-by-case basis; using video or audio teleconferencing to reduce the number of meetings; and having a fixed annual budget (lump sum or itemized) for all of the LAB's operating expenses, with the LAB responsible for securing any additional funding desired through outside grants.

LAB termination. Termination could become a divisive issue if the licensee wants to terminate the LAB but its members (individually or collectively) want to continue, or vice versa. To allow for this, forethought may be needed about who will make the final decision to terminate, and about whether consensus is required for continuation. Controversy over termination may be minimal, however, if all other issues have been handled properly. Then, it may be self-evident to all concerned that the LAB's mission has been completed. Notification of any future plans by the licensee to solicit advice from the public might still be needed, however. This could be done at the time of the $\mathrm{LAB}$ termination.

Resolving differences between the licensee and LAB. The potential for conflict between the LAB and the licensee should not be neglected. Once the LAB is initiated, the licensee and the LAB may need to work together to establish levels of administrative support and operational guidelines. As time goes on, the LAB might make most of its operational decisions by itself. However, the respective expectations and concerns of the licensee and the LAB members may need to be addressed.

Several aspects of $\mathrm{LAB}$ operation are likely to be of concern to the licensee. The licensee is likely to have concerns about costs and time (e.g., an independent facilitator might entail additional costs to the licensee, and certain decision processes might require more time than others). In addition, the licensee may be reluctant to provide the LAB with confidential business information and other information which could easily be misrepresented, taken out of context, or otherwise misused. The licensee may also be concerned if LAB members seek to interview current or former licensee employees.

Given possible differences between the licensee and the LAB (and, possibly, among LAB members), several approaches to conflict resolution could be considered. For example, an outside mediator could be brought in to help reach compromise, in order to ensure that the LAB process forges ahead in a timely fashion. However, the possibility of mediation may dampen desires to work together in a cooperative fashion. Optimally, the licensee and the LAB should 


\section{APPENDIX-A}

develop a strong working relationship with a shared sense of ownership in the outcome of the process and the ability to resolve differences by negotiating with each other.

Allocating implementation responsibilities. The licensee, the NRC, or a neutral outside party or steering committee (possibly selected by the licensee in consultation with the NRC and the state) could take sole responsibility for initiating the LAB process, providing administrative support, offering guidelines on LAB operation, and managing the LAB termination process. Alternatively, these tasks could be allocated according to who would be most appropriate. For example, a steering committee could be established to select LAB members and offer guidelines on LAB operation; the LAB could expand upon those guidelines (and possibly its membership) in consultation with the licensee; the licensee could be responsible for providing a fixed LAB budget limit, with discretion for the expenditure of funds left to the LAB; the NRC, in consultation with the LAB and the licensee, could be responsible for determining when the LAB should terminate. Any number of combinations is possible. The main point is to decide who has the highest likelihood of implementing a part of the process in a manner that will meet the fundamental goals of the LAB concept.

\section{Questions:}

1. What is the optimal size of a $\mathrm{LAB}$, and to what extent should tradeoffs be made between optimal size and inclusiveness? If the LAB's size is kept small, are there effective ways to supplement it in order to ensure adequate representation of stakeholder viewpoints?

2. Who should undertake the preliminary and final process of selecting LAB members?

3. Should the Commission support a policy of providing expenses and/or honoraria to LAB members?

4. What level of financial commitment should a licensee (and/or the NRC) make to a LAB? Should the licensee provide all of the LAB's financial support? How likely is it that the LAB will be viewed as beholden to its financial supporter?

5. How should a licensee balance its desire to protect confidential business information with its obligation to provide information to the LAB?

6. Which cost drivers are most relevant to the operation of a LAB? How can costs be contained without compromising the effectiveness of the LAB? If the LAB's costs were shared, who should be considered as potential cost-sharers?

7. At what point should a LAB be terminated? How should the decision to terminate be made? By whom? Are there license termination issues that could pose a continuing challenge for successor owners or for the licensee and that could justify a post-LAB body? 


\section{APPENDIX-A}

8. How should differences between the licensee and the LAB (and, possibly, among LAB members) be resolved? Are there circumstance under which a mediator should be hired, and if so, by whom?

9. Who should be responsible for implementing a $L A B$ process -- e.g., for initiating the LAB process, providing administrative support, offering guidelines on $\mathrm{LAB}$ operation, and managing termination of the process? 


\section{Issue 4. In the Commission's rulemaking concerning LABs, is a prescriptive or performance-based approach preferable?}

\section{Discussion:}

Prescriptive approaches are means-oriented, whereas performance-based approaches are endsoriented. Prescriptive approaches to rulemaking try to anticipate which design features and methods of implementation are most likely to realize certain objectives, and they then prescribe those features and implementation methods. For example, to ensure representativeness, a prescriptive approach might specify the size and composition of a LAB. In contrast, performance-based approaches to rulemaking focus on the objectives themselves but permit a good deal of discretion in how the objectives are achieved. For example, in a performance-based approach, it might simply be stated that representation of all significant interests should be sought.

There is, however, no bright line between prescriptive and performance-based approaches. Even with prescriptive approaches, objectives are usually articulated and the prescriptions usually include a measure of flexibility. And even with performance-based approaches, certain design features and methods of implementation may be recommended.

In addition, rules rarely spell out all of the details of implementation; they usually are supplemented with regulatory guidelines and other documents. To the extent that rules focus on objectives, with implementation details contained in non-mandatory guidelines, more flexibility is introduced.

Thus, the distinction between prescriptive and performance-based approaches is usually one of degree: they are poles on a spectrum of possibilities. In fact, hybrids of the two are the norm. Nevertheless, it is useful to consider the advantages and disadvantages that a purely prescriptive or purely performance-based approach would offer the Commission, as it sets requirements concerning LABs.

Sub-issues:

Prescriptive approach characteristics. The prescriptive approach ensures that a licensee will not overlook or ignore important considerations in the establishment and operation of an LAB. However, because variations among licensees and affected communities cannot be fully taken into account in rulemaking, highly prescriptive rules can be "Procrustean": they can force all licensees and LABs to fit a limited number of molds. In doing so, they may be burdensome and inefficient. They also may fail to achieve the objectives driving the rulemaking.

Performance approach characteristics. The performance-based approach avoids the inflexibility inherent in a highly prescriptive approach. It allows the licensee and the affected community to tailor the LAB to their particular circumstances by granting a large measure of discretion in 


\section{APPENDIX-A}

determining how the LAB should be set up and operated (and, perhaps, whether one is needed at all or whether another group can fulfill the LAB's roles). With a performance-based approach, however, explicit verification and evaluation measures become especially important. For example, the Commission might want to require the licensee to provide a highly detailed LAB plan for Commission approval, either as part of or following upon the licensee's notification of intent decommission for restricted use. The Commission also might require periodic progress reports on the $\mathrm{LAB}$. Without safeguards, the Commission might have no objective means of determining whether the licensee has actually met the spirit of the regulatory objectives.

\section{Questions:}

1. Issues 2 and 3 addressed, respectively, possible general objectives of an LAB and specific implementation considerations in meeting those objectives. Putting aside the possible substantive content of a rule concerning LABs, how far should the Commission tilt in its rulemaking toward a prescriptive versus a performance-based approach?

2. Would it be helpful to have supplementary guidelines that suggest LAB design features and methods of implementation? What are the advantages and disadvantages of putting prescriptive requirements in the rule versus providing prescriptive guidance in a regulatory guide?

3. If a performance-based approach is used, what measures (apart from the formal evaluations discussed under Issue 6) could the Commission take to ensure that the spirit of its rule concerning LABs is being met? 
Issue 5. Are there special conditions under which a LAB might not be appropriate, where another organization could be used, or where participation by some members would be impeded? Are there special conditions under which a LAB should be required, even though the LAB requirement would normally not apply?

\section{Discussion:}

Some sites proposed for a restricted use decommissioning might not justify the effort and expense of establishing a LAB: for example, sites where the restrictions on future uses are to be an interim, short-lived measure. In contrast, some sites not proposed for a restricted use decommissioning might still merit the establishment of a LAB.

At some sites where the LAB requirement would apply, it could be unnecessary to establish a $\mathrm{LAB}$, because existing organizations could readily be adapted to provide advice on decommissioning issues. Finally, potential barriers to participation by officials may need to be addressed.

\section{Sub-issues:}

Possible exemptions from the $\mathrm{LAB}$ requirement at restricted use sites. In the Background section, the different types of NRC-licensed facilities were summarized. By far the majority of these licensees are users of sealed sources and/or short-lived radionuclides. While contamination from these sources is possible, it is likely to be easily remedied and of short duration. For such materials licensees, restricted use decommissioning is not likely. In contrast, some of the larger materials licensees and most fuel cycle facilities have operations where radioactive contamination may be present on a much greater scale. If a restricted use decommissioning is proposed, and if contamination is extensive, a LAB then may be appropriate. Even then, however, a LAB might not be merited if decontamination was proposed to be achieved with little technical effort and over a relatively short period of time.

Special situations where LABs might be appropriate. A complication arises if, at the time of notification of intent to decommission, it cannot be determined if the site can be cleaned up to permit unrestricted future site uses and thus, if a LAB is needed. A possible remedy is to consider forming an "interim LAB," with the understanding that the nature of the decommissioning plan (i.e., unrestricted or restricted use) is in doubt and needs to be investigated with the help of stakeholder input. In essence, a "tiered" approach to a LAB could be adopted, as some stakeholders have suggested. The licensee could form a LAB whenever it is thought possible that decommissioning may not result in unrestricted use.

Another special situation where a LAB might be appropriate concerns licensees who plan to retain their licenses, but in an amended or modified form. As discussed in the Generic EIS in Support of Rulemaking on Radiological Criteria for Decommissioning (NRC, August 1994), some licensees may propose to undertake activities preparatory to decommissioning (e.g., 


\section{APPENDIX-A}

reducing radioactivity levels, stabilizing the remaining radioactive materials onsite, maintaining or building new waste storage facilities) while not actually decommissioning and seeking license termination. In this situation, it might be appropriate to have a LAB-like body provide advice on the plans being made toward the eventual prospect of decommissioning, especially since these plans could immediately or prospectively affect human health, property values, and local jobs.

Substitutes for LABs. In a number of localities, boards or commissions exist that could substitute for a LAB. For example, a community may have an environmental review board composed of citizen representatives, often with special areas of expertise, that could serve as a LAB. In addition, many communities have elected or appointed boards charged with land use planning and zoning. And some licensees already have advisory boards tasked with soliciting public input on current operations. Either type of group could, conceivably, serve as a substitute for a LAB. Either approach has potential assets and drawbacks.

Creating a LAB out of an existing organization can be time- and cost-efficient and can downplay the controversy that may arise with questions of membership. For example, some LEPCs grew out of existing emergency advisory boards established by states, communities, or chemical companies prior to Congressional passage of SARA. Their transition into LEPCs was easy, because they already had experts and laypeople interested in emergency planning, and their new responsibilities were simply more refined versions of existing activities. Similarly, a LAB formed out of an existing community body or an existing licensee advisory group would avoid duplication of function and would put to use that body's experience. Either the existing body or a subgroup of that body (possibly with additional members) could serve as the LAB. All that might need to be done is to provide the members of this body with additional information and staff support. Organizational duplication is minimized, and the licensee can deal with fewer advisory groups. And with a LAB formed by a local government, there might be an additional advantage: since the most directly affected local units can directly transmit their concerns to other LAB members and vice versa, the legitimacy of LAB recommendations might be strengthened.

However, using a substitute for a LAB could run the risk of distorting the mission of the LAB by tying that mission to existing agendas. Furthermore, the existing group might not have the appropriate expertise (e.g., in land use issues, transportation corridor issues, etc.) for dealing with the proposed decommissioning plan. And, especially with public boards or commissions, they might be charged with an array of responsibilities that could crowd out their attention to LAB matters.

Regardless of whether a licensee forms a $\mathrm{LAB}$ or utilizes an existing organization, the LAB probably will need to interact closely with elected and appointed state and local officials (state radiological protection agencies, occupational safety boards, public health agencies, waste management commissions, local and regional land use planning boards, etc.). Discussion of matters of mutual interest also may need to occur, to ensure that all information pertinent to decommissioning is consistent, clear, and correct. 
Possible impediments to participation on LABs by public officials. Local or state officials may be prohibited or deterred from participating on LABs. Generally, there are two types of possible impediments.

First, public agencies may have regulations that restrict employees from participating in activities that pose a potential conflict of interest with their work; in those cases, participation would have to be written into their jobs. Second, there are potential tort liability concerns. Tort liability addresses the commission or omission of certain acts that might make a public official liable for the consequences of decisions or non-action. Normally, the duties of officials are encompassed under what are termed "governmental functions," which provides protection from liability through "sovereign immunity." However, if a public official performs "proprietary activities" (e.g., those with the potential to produce revenues), they may not be immune from liability.

Issues of sovereign immunity and tort liability for public officials serving on advisory boards arose during the early years of LEPCs. Their experience with this issue may be instructive for LABs. Some states passed laws that made LEPCs "state agencies," thus granting their members automatic sovereign immunity. Another possible alternative is to have representatives of public agencies sit in an ex officio capacity on the LAB. This would temper concerns about their liability, but it also might lessen their input. Fundamentally at issue is whether public agency officials would serve on LABs as representatives of their agencies, or in their personal capacities.

\section{Questions:}

1. Are there conditions under which a LAB might not be needed for a restricted use decommissioning plan? Should a LAB be created if unrestricted use following decommissioning is sought, but may not be attainable? Are "interim" LABs feasible in such instances? Are there other special situations in which LABs might be appropriate?

2. If it is determined that a $\mathrm{LAB}$ is needed at a given site, can another existing group serve as a substitute for the LAB? If so, under what conditions? What problems might be encountered in giving an existing group a LAB's responsibilities? How could these problems be addressed?

3. How should the LAB interact with other advisory groups or similar organizations to ensure compatibility with their missions? What groups should a LAB consult in performing its public advisory functions for licensees?

4. Are there impediments to participation on LABs by public officials? How should these impediments be addressed? Should public officials be expected to serve on a LAB in a public or personal capacity? 


\section{APPENDIX-A}

Issue 6. How should the effectiveness of LABs be evaluated, and what are the regulatory implications of LAB evaluations?

\section{Discussion:}

Given that LABs have never been used as a formal mechanism for public participation in site decommissioning plans, initial guidelines concerning LABs may need to be modified in light of subsequent evaluations. However, the lack of experience with LABs means that the development of a structured evaluation plan would be based in part on speculation about which factors or performance measures should and can be studied.

In its proposed rule, the Commission does not specify a process for evaluating LABs. One option would be to conduct a series of case studies when a few LABs have been attempted. These studies would not use a formal evaluation framework; they would simply describe several LABs' experiences. Through these descriptions, a more structured evaluation approach could be developed. This would capture the results of actual experience while approaching evaluation realistically.

Sub-issues:

Purposes of an evaluation. An evaluation could have several purposes. One might be to identify difficulties in convening a $\mathrm{LAB}$. This information could be used to refine the procedures future licensees should employ. Another purpose might be to identify difficulties LAB members have in understanding the technical issues surrounding decommissioning. If LABs have such difficulties, this could point the way to improvements needed in technical or administrative resources.

Evaluation could also address whether or not LABs have been convened in a timely manner, and whether their advice has made a difference in subsequent licensee and NRC decisions.

Evaluations could be done of individual LABs, either to make mid-course corrections or as a "post-mortem." In addition, evaluations could be done of a suite of LABs, to suggest to the NRC whether changes in regulations and guidelines might be advisable.

Performance criteria and indicators. Evaluation questions are often framed in terms of the degree to which an activity meets its objectives. Indicators of effectiveness then need to be specified and methods for their measurement established. An example of a possible criterion for gauging LAB effectiveness is timeliness of advice (see Issue 2). This can be assessed by observing the points at which $\mathrm{LAB}$ advice was solicited and incorporated into the development of the decommissioning plan.

Another possible criterion might be short-term efficiency, defined as achieving LAB goals and objectives with a limited expenditure of resources. This can be assessed by determining the total time and money invested in a LAB effort by its participants, the licensee, and the NRC, and then comparing this qualitatively with the output of the effort. To provide balance, a criterion of long- 
term efficacy might also be worth evaluating. Although LABs will be encompass many different stakeholder groups that will vary from site to site, one indicator of long-term efficacy could be acceptance of LAB findings by stakeholder constituencies. For example, if a LAB's advice is determined to be consistent with the future land use goals of a local community, then it can be estimated that service to a local land use-oriented constituency has been achieved.

Responsibility for evaluation. Someone must be responsible for conducting evaluations of LAB effectiveness. If the NRC is undertaking an evaluation of the LAB effort as a whole, it likely would use professional assistance together with licensee and LAB input. If individual evaluations tailored to a particular LAB are undertaken, one option is to have the licensee conduct the evaluation. However, while close to its subject, the licensee may lack a disinterested perspective. Another option is to retain an independent evaluator. This would add to the cost of a LAB and does not settle the matter of who should hire the outside evaluator. A compromise might be to have the licensee undertake the evaluation with outside evaluator assistance. Finally, individual LABs might perform self-evaluations, either periodically during their existence or at the close of their efforts.

Evaluation timing. Outcomes of evaluation are often dependent upon when they are done. As suggested above, preliminary evaluations could be performed while the LAB is being convened and when it is actively working with the licensee on the decommissioning plan. This is sometimes referred to as "process evaluation." While possibly disruptive to LAB activities, a process evaluation might identify problems in LAB operations that might be less evident (and certainly would be less correctable) if evaluation was performed only at LAB termination. Nevertheless, the overall impact of the LAB on decommissioning planning may be more readily assessed at the conclusion of its efforts.

Use of evaluation results. Evaluation results can be used in many ways. As noted above, they can be used for mid-course corrections by individual LABs, and they can be used by the Commission to help refine guidelines. In addition, one use might be to inform a licensee about how other LABs have been developed and how their recommendations have been used.

Evaluation results then provide informal guidance on strategies that work and pitfalls to be avoided. Similarly, when a LAB is convened it might wish to review evaluations of other LABs, to help understand what other LABs have done and difficulties they have faced.

In any case, the ways in which evaluation results are reported should take into consideration who will use them. For example, if the results are to be used by LABs, then evaluation studies probably should be non-technical. LABs may benefit more from case studies than from highly structured evaluations. In contrast, the Commission may be most interested in evaluations that systematically characterize and discuss findings from a number of LABs along several dimensions. More than one type of evaluation may be needed if their users are diverse.

When an evaluation is of little value. There may be circumstances under which there is little point in conducting an evaluation, especially if it is to be used mainly to provide insights for the 


\section{APPENDIX-A}

Commission and other LABs. For example, if a LAB is convened only fleetingly, there may be an insufficient basis on which to complete an evaluation. Also, if a particular site undergoing decommissioning is unusual (e.g., very small or remote), it may be unrepresentative of problems likely to arise at other restricted use decommissioning sites. Then, an evaluation might still be useful for "self-help" purposes, but its results probably would not be generalizable.

Regulatory implications of LAB evaluations. Cumulative evaluations of several LABs could lead to changes in the LAB requirement. The Commission or its licensees may want to modify the LAB approach. Alternatively, the Commission might decide that the LAB approach should be abandoned, or it might decide that the LAB approach should be extended to other circumstances in either its current or a revised form. As discussed in Issue 5, an amended or modified license, wherein the licensee plans to store radioactive materials on-site, might suggest the need for a LAB to advise on the development of the storage plan. And even in instances of license termination, decommissioning and post-decommissioning issues might necessitate further stakeholder consultation in a small-group setting.

\section{Questions:}

1. What purposes should an evaluation serve? What should be done with the results of an evaluation? How should they be used to inform the LAB process?

2. Can objectives such as those discussed in Issue 2 be used as the basis for criteria in a LAB evaluation? Are there ways in which they should be modified to make them more useful as evaluation tools?

3. Are there clear indicators of LAB effectiveness? Should short-term cost-effectiveness and long-term payoffs be included as evaluation criteria? If so, what measurement indicators should be used?

4. Who should be responsible for evaluating LAB effectiveness? The licensee? The Commission? An independent evaluator? Should the LAB do its own self-evaluation in conjunction with an external evaluation?

5. When should an evaluation be done? Should it be done for each LAB at the same time? Should a global evaluation be done by the Commission of all LAB's in a given time period (e.g., a year after implementation)?

6. Are there circumstances under which conducting an evaluation would be pointless or of limited utility?

7. Should a "sunset clause" be incorporated that would provide for automatic review and possible termination of the LAB approach? If so, after how many years? 
8. At what point should consideration be given to extending the LAB approach to other site decommissioning situations?

9. Should licensees be encouraged to individually or collectively petition the Commission for changes in the LAB approach, if they have evidence that it would work better in a modified form? What would count as good evidence? 


\section{APPENDIX-A}

\section{GLOSSARY OF TERMS AND ACRONYMS}

Agreement State: any state that has entered into an agreement with the Atomic Energy Commission or the Nuclear Regulatory Commission under Section 274b of the Atomic Energy Act to license and regulate nuclear facilities.

CAC: Citizens' Advisory Committee.

Commission: U.S. Nuclear Regulatory Commission (NRC).

decommissioning: Under the proposed rule (59 FR 43230), decommissioning is defined as removing a facility or site safely from service and reducing residual radioactivity to a level that permits (1) release of property for unrestricted use and termination of the license, or (2) release of the property under restricted conditions and termination of the license.

decontamination: the process of reducing levels of radioactive contaminants in or on materials, structures, or equipment.

Delphi technique: a formal, iterative process used for group decision-making to elicit preferences and refine a range of alternatives. The process involves a written questionnaire, with a feedback summary and follow-up questionnaire, repeated in one or more rounds until the final points of agreement and disagreement have been clarified.

DOD: United States Department of Defense.

DOE: United States Department of Energy.

EIS: Environmental Impact Statement, under NEPA.

$E M F$ : electromagnetic fields.

EPA: United States Environmental Protection Agency.

ex officio: by virtue or because of an office.

FFER: Federal Facilities Environmental Restoration.

FONSI: Finding of No Significant Impact, under NEPA.

$L A B$ : Licensee Advisory Board.

LEPC: Local Emergency Planning Committee. 


\section{APPENDIX-A}

licensee: the holder of a license; in this context, a license issued by the NRC for radioactive material.

mrem: milli-rem, one-thousandth of a rem. Rem (from roentgen equivalent man) is a unit of effective radiation dose, or dosage of ionizing radiation that will cause a specific level of biological effect.

NEPA: National Environmental Policy Act.

$N R C$ : U.S. Nuclear Regulatory Commission.

performance-based approach: an approach where the intended outcomes are specified and the means to achieve those outcomes are not specifically defined.

prescriptive approach: an approach where the required procedures are explicitly defined (prescribed) in order to meet the intended outcomes.

$R A B$ : Restoration Advisory Board (to DOD).

restricted use: future site use, following license termination, where land use is restricted in some way.

SARA: Superfund Amendments and Reauthorization Act.

SDMP: Site Decommissioning Management Plan.

sealed source: radioactive material that is encased in a capsule designed to prevent leakage or escape of the material.

SSAB: Site-Specific Advisory Board.

sovereign immunity: The status of legal protection from personal lawsuits granted to public officials. Its purpose is to protect them from being sued when they carry out the normal duties of their offices honestly and forthrightly, even if those duties result in harm to someone.

stakeholder: an interested and affected party.

TEDE: Total Effective Dose Equivalent.

tort liability: The legal status of public officials who knowingly, unknowingly, or negligently commit acts that violate their duties as public officials (e.g., failure to exercise good judgement). In such instances, these officials can be sued. 


\section{APPENDIX-A}

unrestricted use: future site use, following license termination, for any purpose, public or private. 


\section{APPENDIX B}

PARTICIPANTS AT THE WORKSHOP 
PARTICIPANT LIST

NRC WORKSHOP ON THE USE OF SITE SPECIFIC ADVISORY BOARDS DECEMBER 6, 7, \& 8, 1994 - HALL OF THE STATES, WASHINGTON, D.C.

\section{CITIZEN/ENVIRONMENTALIST}

Dianne Quigley

Childhood Cancer Research Institute

747 Main Street

Concord, Ma 01742

508-287-0023

Fax 508-287-0025

Debbie Katz

Citizens Awareness Network

P.O. Box 242

Charlemonte, Ma 01339

413-339-8768

Mike Veiluva

Western States Legal Foundation

1440 Broadway

Suite 500

Oakland, CA 94612

510-839-5877

Fax 510-839-5397

Glenn Carroll

Georgians Against Nuclear Energy

139 Kings Highway

Decatur, GA 30030

404-378-9542

Lance Hughes

Native Americans for a Clean Environment

P.O. Box 1671

Tahlequah, OK 74465

918-458-4322

Fax 918-458-0322

\section{ENVIRONMENTAL EOUITY}

Damu Smith

Greenpeace

1436 U Street, NW

Washington, DC 20009

202-462-1177

Fax 202-462-4507

\section{TRIBAL INTERESTS}

Robert Cook

Yakima Indian Nation

P.O. Box 151

Toppenish, WA 98948

509-865-5121

Katherine Maxwell/Byron Brown, Tribal Council

Narragansett Indian Tribe

P.O. Box 268

Charlestown, RI 02813

401-364-1117

Darlene Roach/Darelynn Lehto, Tribal Council

Mdewakanton (Prairie Island) Tribal Council 5750 Sturgeon Lake Road

Welch, MN 55089

800-554-5473 X4108

Robert Holden

National Congress of American Indians

900 Pennsylvania Avenue, SE

Washington, DC 20003

202-546-9404

Fax 202-546-3741 


\section{LOCAL GOVERNMENT}

Phil Niedzielski-Eichner

Governmental Dynamics Inc

P.O. Box 221274

Chantilly, VA 22022

703-818-2434

Fax 703-818-2434

Cindee Virostek

Councilwoman

Apollo Borough Council

409 N 8th Street

Apollo, PA 15613

412-478-2351

Fax 412-567-7925

Kathy Edwards, Mayor

Village of Newburgh Heights

4000 Washington Park Blvd.

Newburgh Heights, OH 44105

216-641-4650

Seth Kirshenberg

International CitylCounty Management

Association

777 N. Capitol Street, NE

Suite 500

Washington, DC 20002-4201

202-962-3663

\section{STATE GOVERNMENT INTERESTS}

Bob Kulikowski

Organization of Agreement States

Bureau of Radiological Health

New York City Department of Health

New York, NY 11201

718-643-7967

Fax 718-643-4616
Bill Dornsife

Council of Radiation Control Program

Directors

Bureau of Radiation Protection

Pennsylvania Department of Environmental

Resources

Sulton Building

Third and Locust Streets

Box 8469

Harrisburg, PA 17101-8469

717-787-248

Fax 717-783-8965

Ron Ross

Western Governors Association

60017 th Street

Suite $705 \mathrm{~S}$

Denver, CO 80202

303-623-9378

Brian Zwit

National Association of Attorney Generals

444 North Capitol Street, NW

Suite 339

Washington, DC 20001

202-434-8041

Fax 202-434-8058

\section{INDUSTRY}

Lynette Hendricks

Nuclear Energy Institute

1776 Eye Street, NW

Suite 300

Washington, DC 20006

202-739-8109

Fax 202-785-7898

David Nichols

American College of Nuclear Physicians

1200 19th Street, NW

Suite 300

Washington, DC 20036

202-429-5120

Fax 202-223-4579 
Ralph DeSantis

GPU Nuclear Corporation

TMI Communications Office

P.O. Box 480

Middleton, PA 17057

717-948-8197

Fax 717-948-8723

Mark Doruff

Medi-Physics, Inc.

2636 South Clearbrook Drive

Arlington Heights, IL 60005-4692

708-593-6300 X309

Fax 708-437-1699

Joe Cepicka

Babcox and Wilcox Nuclear Environmental

Services, Inc.

RD \#1, Box 355

Vandergrift, PA 15690

412-842-1488

Fax 412-842-1478

Federal Express Address: Rt. 66 River Road

Leechburg, PA 15656

Jim Murray

Murray Lamont and Associates

1660 Wynkoop

Suite 1060

Denver, CO 80202

303-825-2802

\section{FEDERAL AGENCIES}

Cindy Kelly, Director

Don Beck, Deputy Director

Office of Public Accountability

EM5; Room 5B-031

U.S. Department of Energy

Forrestal Building

1000 Independence Avenue

Washington, DC 20585

202-586-7633
Marcia Read

Office of the Deputy Undersecretary

Department of Defense

3400 Defense Pentagon

Washington, DC 20301-3400

703-697-9763

Fax 703-695-4981

Richard Jubie

Environmental Protection Agency

Office of Solid Waste

Federal Facilities Program

401 M Street, SW

Washington, DC 20460

202-260-5686

Fax 202-260-5646

\section{U.S. NUCLEAR REGULATORY}

COMMISSION

Dr. Donald A. Cool, Chief

Radiation Protection Regulations Branch

Division of Regulatory Applications

Office of Nuclear Regulatory Research

U.S. Nuclear Regulatory Commission

Washington, DC 20555

301-415-6187

Michael F. Weber, Section Leader

LLW and Decommissiong Projects

Division of Waste Management

Office of Nuclear Material Safety and

Safeguards

U.S. Nuclear Regulatory Commission

Washington, DC 20555

301-415-7298

Francis S. Cameron

Special Counsel for Public Liaison

And Agreement State Programs

Office of the General Counsel

U.S. Nuclear Regulatory Commission

Washington, DC 20555

301-504-1642

Fax 301-504-3200 


\section{RESOURCES}

Dave Feldman

Energy, Environment, and Resources Center University of Tennessee 327 South Stadium Hall

Knoxville, Tn 37996-0710

615-974-4251

Fax 615-974-1838 
APPENDIX C

COMMENT REFERENCES 


\section{APPENDIX C - COMMENT REFERENCES}

This appendix can be used to determine the origin of each comment and where each comment is used in this report. The listed information includes a comment number, the particular summary sections (issues) to which it contributes, the last name of the commenter, and the page of the transcript on which the comment begins.

About half of the comments are used in more than one summary section, but the comment number is unique and remains with the comment in each summary section where it is used. For example:

Comment Report

Number Section

Name

In this example, comment number 3 is used in Sections 2.1.2, 2.2.3, and 2.4.1 of this report. The name of the commenter is listed; and the comment begins on page 15 of the transcript of proceedings.

The following pages contain a column listing of these data per comment number. 
Comment Report

Number Section

MAXWELL

HENDRICKS

HENDRICKS

NICHOLS

NICHOLS .20 
Comment Report

Number section

17

2.1 .2

2.1 .1

2.2 .1

2.4 .2

20

21

22

23

24

25

2.1.1

2.1 .2

2.2 .1

2.2 .2

2.5.2

26

2.3.2

2.4 .2

27

2.2 .4

2.6 .2

28

29

30

2.5 .1
2.7 .1

2.1.2

2.5 .2

2.1 .2

2.1 .4

212

2.4 .1

2.4 .2

2.1 .2
Name

Page

BECK 23

DORUFF .24

DORUFF 24

BERLIN .25

ROACH 25

ZWIT 26

2.1.1 KATZ 27

ZWIT 27

28

KATZ 28

KATZ .28

KATZ 29

DESANTIS 30

QUIGLEY

CEPICKA 31 
Comment Report

Number Section

31

2.1.2

2.2 .1

32

2.1.2

2.4.1

2.4 .2

33

2.1.1

2.1.2

2.7 .2

34

2.1 .2

2.3 .2

2.1.1

2.2 .1

36

37

38

2.1.1

2.1 .2

2.5 .2

39

2.3.2

40

2.4 .1

41

2.2.1

2.2 .3

2.4 .1

2.4 .2

42

2.2 .1

43

2.1.1

44

2.3.2

45

2.4.1

46

2.2 .1

Name

Page

CEPICKA

VIROSTEK

32

EDWARDS

32

EDWARDS

EDWARDS 33

EDWARDS 34

FELDMAN 36

FELDMAN 38 
Comment Report

Number section

47

2.3 .2

2.3.1

2.3.2

49

50

51

52

53

54

55

56

57

58

59

2.1.1

2.2.1

2.5 .1

60

2.2.1

2.2 .4

2.5 .2

61

62

2.5 .2

2.1 .4

2.7 .4

2.3.2

2.1.2

2.2.1

2.2.1

2.6 .2

2.1 .2

2.5 .2

2.1 .2

2.1.2 FELDMAN

Name

Page

FELDMAN 51

FELDMAN 53 56

FELDMAN 58

COOK

COOK

FELDMAN 65

FELDMAN

66

FELDMAN 67

BECK

68

BECK

BECK

BECK 73

BECK 73

BECK 72 . 
Comment Report

Number Section

2.1 .2

63

64

2.1.2

2.4 .2

65

2.1 .2

2.4 .3

2.6.1

67

2.1 .1

2.1.2

68

2.2 .1

2.5.2

69

2.2.1

2.2 .2

70

2.2.1

2.5 .2

71

2.2.1

2.6.1

2.6 .2

72

2.2 .2

2.3.2

73

2.2 .4

2.5.1

2.6.2

74

2.1 .2

KAISER

83

75

2.1 .1

2.2.1

KAISER

89

77

Name

Page

BECK

.75

.76

BECK

.76

BECK

76

BECK

77

BECK

78

78

79

BECK

BECK

.80

76

KAISER

2.2 .4

KAISER 
Comment Report

Number section

78

2.1.2

2.4 .1

2.4 .2

79

2.3.1

2.6.1

80

2.1 .2

2.4 .1

2.4 .2

81

82

83

84

85

86

87

2.1.1

2.1 .2

2.2 .2

88

2.1 .1

BECK

Name

Page

BECK

BECK

2.6 .2

BECK

2.1 .1

BECK 94

2.1.1

2.4 .3

2.1.1

2.1 .2

2.1 .2

VEILUVA

2.1 .2

BECK

89

2.1 .2

KAISER

90

2.1 .2

KAISER

104

91

2.2 .4

2.6 .2

92

2.2 .1

BECK 106

93

BECK 


\begin{tabular}{|c|c|c|c|}
\hline APPENDIX & $\mathrm{xC}$ & & COMMENT REFERENCES \\
\hline Comment & Report & & \\
\hline Number & Section & Name & Page \\
\hline 94 & $\begin{array}{l}2.2 .2 \\
2.7 .2\end{array}$ & NIEDZIELSKI-EICHNER & .. 107 \\
\hline 95 & $\begin{array}{l}2.1 .2 \\
2.7 .2\end{array}$ & NIEDZIELSKI-EICHNER & . . 108 \\
\hline 96 & $\begin{array}{l}2.4 .2 \\
2.4 .3 \\
2.6 .2\end{array}$ & COOK $\ldots$ & $\ldots 110$ \\
\hline 97 & $\begin{array}{l}2.2 .1 \\
2.5 .2\end{array}$ & BECK & $\ldots 111$ \\
\hline 98 & $\begin{array}{l}2.3 .2 \\
2.4 .3\end{array}$ & BECK & $\ldots 112$ \\
\hline 99 & $\begin{array}{l}2.2 .1 \\
2.3 .2 \\
2.5 .2\end{array}$ & BECK & $\ldots 112$ \\
\hline 100 & $\begin{array}{l}2.2 .1 \\
2.5 .2\end{array}$ & BECK & $\ldots 113$ \\
\hline 101 & $\begin{array}{l}2.2 .4 \\
2.6 .2\end{array}$ & BECK & $\ldots 114$ \\
\hline 102 & 2.1 .1 & KAISER $\ldots \ldots \ldots \ldots$ & $\ldots \ldots \ldots \ldots 115$ \\
\hline 103 & 2.1 .1 & KAISER $\ldots \ldots \ldots \ldots$ & $\ldots \ldots \ldots \ldots \ldots 116$ \\
\hline 104 & $\begin{array}{l}2.1 .1 \\
2.1 .2 \\
2.1 .4\end{array}$ & CARROLL ... & $\ldots 123$ \\
\hline 105 & $\begin{array}{l}2.1 .1 \\
2.1 .2\end{array}$ & KULIKOWSKI $\ldots \ldots \ldots$ & $\ldots \ldots \ldots \ldots \ldots \ldots 124$ \\
\hline 106 & 2.1 .2 & KULIKOWSKI & $\ldots 126$ \\
\hline 107 & $\begin{array}{l}2.1 .1 \\
2.1 .2\end{array}$ & KATZ & $\ldots 126$ \\
\hline 108 & 2.1 .1 & HENDRICKS & . . 128 \\
\hline NUREG/CR- & -6307 & $C-8$ & \\
\hline
\end{tabular}


Comment Report

Number section

109

2.1.1

2.2.1

2.6.1

2.6.2

110

2.1.4

111

2.1.1

2.1 .2

112

2.1 .4

113

2.1.1

$114 \quad 2.1$.

2.1.4

115

2.1.1

2.1 .3

2.1 .4

116

2.1.1

2.1 .2

2.1 .4

2.2 .1

117

2.2.1

2.4.1

2.7 .2

118

2.1.1

2.1.2

2.2.1

119

2.1.1

2.1 .2

2.2 .2

120

2.2 .2
ZWIT

ZWIT

NIEDZIELSKI-EICHNER

Name

Page

130

131

COOK

COOK

248

MURRAY

249

MURRAY

249

MURRAY

250

KATZ

C- 9

NUREG/CR-6307 
Comment Report

Number Section

121

2.1.1

2.2 .1

2.4 .2

2.6 .2

122

2.2 .1

2.5 .2

123

2.1.2

2.2.1

2.4.3

2.6.1

2.7 .2

124

2.6 .1

VIROSTEK 253

125

2.3 .2

126

2.1.1

2.1.2

2.1 .4

2.2 .1

2.4.1

2.4 .2

127

2.1.2

2.4 .2

128

2.2 .4

2.1 .2

2.2 .4

130

2.1.1

2.2 .1

131

2.1 .1

2.2.1

2.7 .1

132

2.7 .1

2.7 .2

Name

Page

VIROSTEK

VIROSTEK

253

VIROSTEK

253

VIROSTEK

.254

VIROSTEK

258

HENDRICKS

.259

HENDRICKS 259

VEILUVA 262

VEILUVA 263

MAXWELL .264 
Comment Report

Number section

133

2.1.3

2.2 .1

2.4 .2

2.7 .2

134

2.4.1

2.4 .2

2.7 .2

135

2.1.1

136

2.3 .2

2.2.3

2.4 .2

138

2.1.1

2.1 .3

2.2 .2

2.2 .3

139

2.1.1

2.5.1

140

2.1.1

2.5.1

141

2.1.1

CEPICKA

Name

Page

MURRAY

266

MURRAY

267

2.1.2

2.2 .1

143

2.4 .2

2.7 .2

144

2.1 .4

COOK

276

145

2.1.1

2.7 .1

146

2.2.1

COOK

277 


\section{APPENDIX C}

Comment Report

Number Section

147

2.1 .2

2.2 .3

2.3.2

2.7.1

148

2.1 .4

2.2 .1

149

2.1 .2

2.7 .2

150

2.1 .1

2.1 .4

151

2.2 .2

152

2.1 .2

2.7 .3

153

2.1.1

2.1.2

2.1.3

2.1.4

2.2 .2

154

2.1.2

2.2.1

2.4 .3

2.6.1

155

2.1 .1

2.2 .1

2.4 .3

2.6.1

157

2.1 .1

2.1.1

158

159

2.1 .4

2.7.1

160

156

Name

Page

COOK 279

COOK 279

KULIKOWSKI 282

KULIKOWSKI 283

KULIKOWSKI 284

KULIKOWSKI 285 ZWIT 289

ZWIT 292

ZWIT 292 291

ZWIT .293

QUIGLEY .294

NIEDZIELSKI-EICHNER .294

NIEDZIELSKI-EICHNER .294 
NIEDZIELSKI-EICHNER

2.7.1

2.7.2

162

2.1 .2

NIEDZIELSKI-EICHNER 295

2.2.1

2.6.1

163

2.1.1

NIEDZIELSKI-EICHNER 296

164

2.1 .1

HENDRICKS

297

165

2.1 .1

HENDRICKS 298

166

2.1 .1

HENDRICKS 299

2.1 .2

2.6 .1

167

2.1 .1

VEILUVA 300

168

2.1 .2

VEILUVA 300

2.2 .1

2.6.1

169

2.1.1

VEILUVA

2.7.1

170

2.7.2

VEILUVA 301

171

2.1.4

VEILUVA 301

172

2.1.1

VEILUVA 303

2.1.2

2.2 .1

2.2 .4

2.5.2

2.6 .1

173

2.1.1

DORUFF 304

2.1.3 


\section{Comment Report}

Number Section

174

2.2 .4

2.4 .3

2.6.1

2.6.2

175

2.1.2

2.2 .1

2.3 .2

176

2.2 .1

2.2 .1

2.4.1

2.5 .2

179

2.1 .1

2.2 .1

2.1.1

2.1.4

2.2 .1

183

2.2 .1

2.7.1

2.2.1

2.7.1

186

2.2 .1

2.1 .1

2.3.2

2.5.1

2.5 .1
2.7 .1

189

177
178
179

187

188

CARROLL

$$
\text { KATZ }
$$

$$
\text { KATZ }
$$

$$
\text { KATZ }
$$

$$
\text { KATZ }
$$

HENDRICKS 316

\section{HENDRICKS}

\section{CAMERON 318}

COOK

COOK .319

COOK .320

COOK 320

COOK .321

COOK

$$
\mathrm{ROACH}
$$

2.3 .2
2.7 .1


Comment Report

Number section

190

2.1 .1

2.7 .1

2.3 .2

2.4 .1

2.4 .2

2.4 .3

193

2.2.1

2.7.4

194

2.2 .1

2.4 .2

2.1.1

2.1 .2

197

2.1.1

2.1 .2

2.1 .3

198

2.2.1

2.3.2

2.4 .2

199

2.1.1

2.1.2

2.1 .3

2.2 .1

200

2.2.1

2.3.2

2.4 .1

201

2.4 .2

2.4 .3

202

CARROLL

325

CARROLL

326

CARROLL 326

CARROLL 327

CEPICKA

CEPICKA

KIRSHENBERG

KIRSHENBERG

.331

KIRSHENBERG 


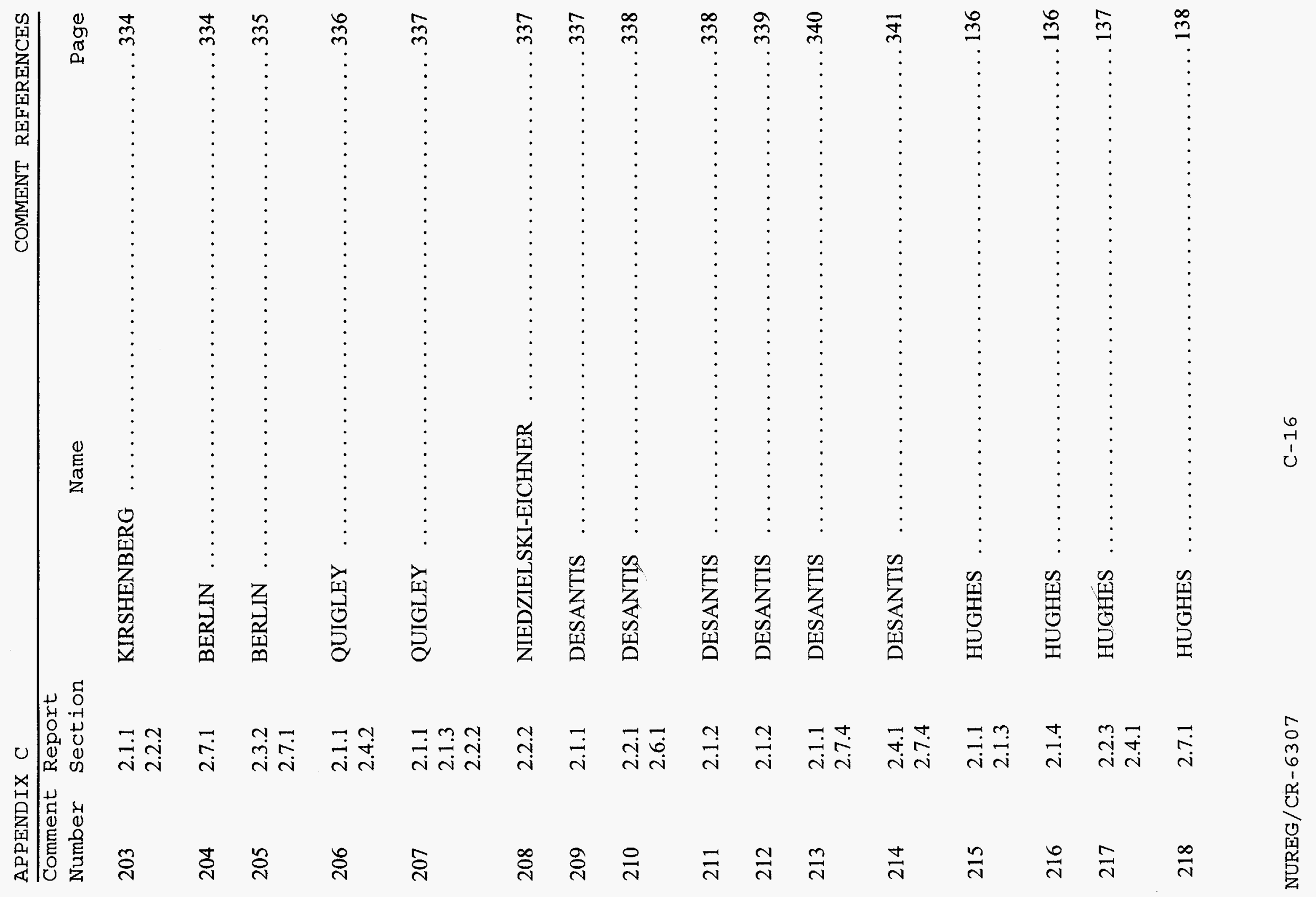


Comment Report

Number Section

219

220

222

223

224

225

226

2.1.1

2.1.2

2.2 .2

227

2.1.1

2.1.2

2.1 .3

228

2.7 .3

229

2.1.1

230

2.3 .2

2.7 .2

2.7 .2

2.2 .1

2.2 .1

2.1 .1

2.1 .2

2.4 .2

6.2

231

232

(n)

HUGHES

Name

Page

138

VEILUVA

VEILUVA

VEILUVA 140

VEILUVA 140

VEILUVA

QUIGLEY

QUIGLEY

143 
APPENDIX C

Comment Report

Number

Section

2.1 .1

2.1 .2

234

2.1.2

2.4.1

2.4 .2

236

2.1 .1

2.1.1

237

238

2.3.2

2.7.1

239

2.1.1

2.1.2

2.1 .3

2.2.1

2.2 .2

240

2.2 .2

241

2.3 .3

242

2.1 .2

243

2.3.2

2.7.1

244

2.2 .3

2.6 .1

2.6.2

245

2.1.2

2.2 .2

246

2.2 .1

247
Name

Page

DESANTIS

150

DESANTIS

150

DESANTIS

DESANTIS

COOK

COOK

KATZ

KATZ 154

KATZ

KATZ

HUGHES

HUGHES

HUGHES 158

HUGHES 159

HUGHES 159 
Comment Report

Number Section

248

2.2 .3

2.4 .1

2.6 .2

249

2.7 .4

250

2.1 .1

251

2.1.1

252

2.1.1

2.1 .2

2.1 .3

253

2.2.2

2.3.2

2.7.2

254

255

256

257

258

259

260

2.4.2

2.5.1

2.7.1

261

2.2 .3

2.7 .3

262

2.2 .3

2.7 .1

2.7 .2

263

2.1 .1
Name

Page

CARROLL 161

CARROLL 162

HENDRICKS 163

HENDRICKS 166

NIEDZIELSKI-EICHNER 167

NIEDZIELSKI-EICHNER 168

QUIGLEY 169

QUIGLEY 170

DORUFF 171

DORUFF 172

NICHOLS 175

BERLIN 176

BERLIN 177

COOK 179

COOK 179

COOK 180 2.1 .4 
Comment Report

Number Section

264

2.2 .3

2.3.1

2.7.1

265

2.1 .1

2.2 .2

2.1.4

2.1 .2

268

269

2.2 .1

2.3.2

270

2.2 .1

3.2

271

2.1.2

272

2.1.1

2.4.1

2.5.2

273

2.2.2

2.7 .2

274

2.2 .3

2.3.2

2.4 .1

2.5.2

275

2.1.1

2.1 .4

276

2.1.4

2.3 .2

277

2.1.1

2.2 .2

2.2 .3

2.6 .2
Name

Page

COOK

181

KIRSHENBERG

KIRSHENBERG 184

VEILUVA 187

VEILUVA 187

FELDMAN

FELDMAN

$$
\text { KATZ }
$$

$$
\text { KATZ }
$$

KATZ

192

HUGHES

194

HUGHES

HUGHES

HUGHES

NUREG/CR- 6307

$$
\text { C- } 20
$$


Comment Report

Number section
Name

Page

278

2.1.1

2.2 .3

279

2.1 .1

HENDRICKS

199

280

2.1 .4

HENDRICKS 200

281

2.7 .2

HENDRICKS

202

282

2.7 .2

NIEDZIELSKI-EICHNER .203

283

2.1.1

2.1 .2

284

2.7 .2

NIEDZIELSKI-EICHNER 204

285

2.1 .2

DESANTIS

205

286

2.1 .1

CEPICKA 207

2.1.2

2.4 .2

287

2.1.2

CEPICKA 208

288

2.4 .2

CEPICKA 208

289

2.1 .1

COOK .209

290

2.1 .2

EDWARDS

2.7 .2

291

2.2 .3

EDWARDS

2.2 .4

2.6 .1

2.6 .2

2.7 .2

292

2.1 .1

CARROLL

213

293

2.1.1

ZWIT 215 
Comment Report

Number Section

294

2.1 .2

2.1 .4

295

2.7 .2

2.7 .2

2.7 .2

2.7 .2

2.7 .4

2.1.2

2.2 .3

2.4 .2

2.7 .2

301

2.1.1

2.2 .1

2.6.2

303

2.1 .2

2.5 .1

304

2.1 .4

2.7.4

2.1.2

2.2.2

307

2.7.4

2.5.1

2.1.2

309

310

2.7.4

2.1.2 2.7.4

311
Name

Page

VIROSTEK 216

VIROSTEK 216

CAMERON 219

NIEDZIELSKI-EICHNER 220

KATZ .222

KATZ .223

VIROSTEK 223 227 229

LUX

OLSEN 230

OLSEN 232

OLSEN 232

OLSEN .232

OLSEN 233

OLSEN 233

OLSEN .233 


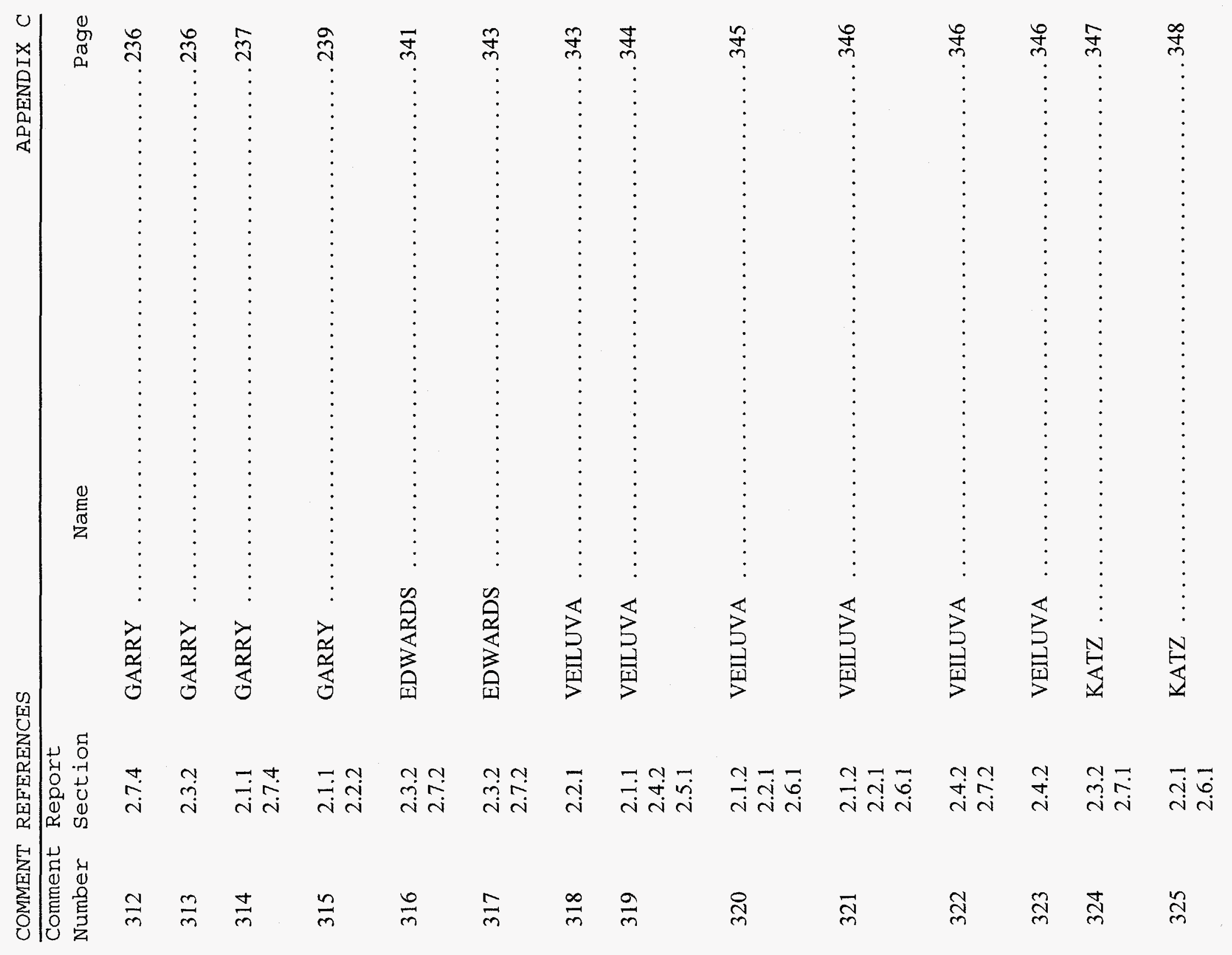


APPENDIX C

Comment Report

Number section

$326 \quad 2.4 .1$

2.4.2

2.5 .2

327

2.2.1

2.7 .4

328

2.2 .1

2.7.4

329

2.2.1

2.7 .4

330

2.2.1

2.4.1

2.6.1

331

2.2 .1

2.7.1

332

2.1.2

2.1.1

2.1 .2

2.2.1

334

2.4 .2

2.7 .2

335

2.3 .2

2.5.1

2.6 .2

337

2.1.1

2.1 .2

2.7.2

338

2.4 .2

339

2.1 .1

2.1 .2

2.1.3

336

.

VIROSTEK 349

COOK 350

COOK 350

COOK

COOK 353

COOK 354

CLOUD 356

CLOUD 356

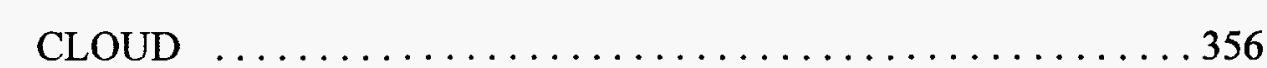

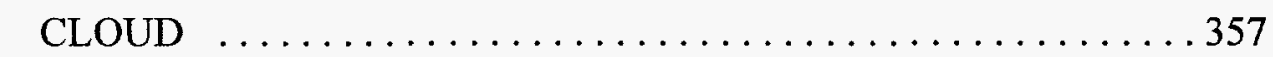

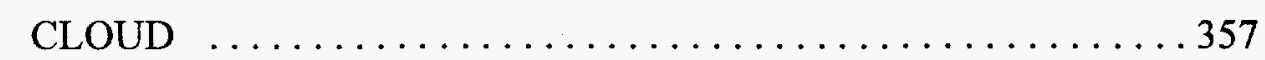

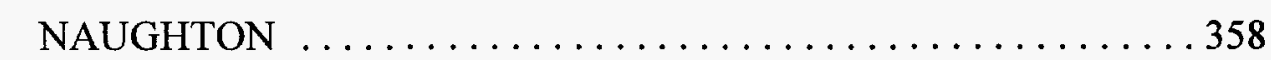


Comment Report

Number Section

340

2.1.1

2.2 .2

341

2.1.1

2.2 .2

2.7 .4

342

2.1.1

2.1 .2

2.3.2

2.4 .2

2.7 .2

343

2.4 .2

2.6.1

2.7.1

345

2.1.1

2.1.2

2.7.1

2.7 .2

346

2.1.1

2.1.2

347

2.1.1

2.1.2

2.2.1

348

2.1.1

2.1.2

2.7.4

349

2.4 .3

2.6.1

350

2.1.2

2.1.3

2.2 .1

Name

Page

KILLAR

360

KILLAR

361

KILLAR

.361

KILLAR .361

KILLAR 362

$$
\text { KILLAR }
$$
362 
Comment Report

Number

Section

2.2 .1

2.4.1

2.4 .2

353

2.7 .4

CARROLL

Name

Page

CARROLL

374

2.1.1

2.2 .2

355

2.3.2

2.7 .2

356

2.2 .2

ZWIT 378

357

2.1.1

2.1.2

358

2.1.2

2.2.1

359

2.1.1

2.1 .4

2.7 .4

360

2.2 .2

2.2 .3

2.3.1

2.7.2

361

2.2.1

2.3.2

2.5.2

362

2.5 .2

QUIGLEY

388

363

2.2 .2

QUIGLEY

388

364

2.5 .2

COOK

389

365

2.1 .2

HENDRICKS

366

2.2 .2

KATZ

394 


\section{Comment Report}

Number Section
Name

Page

367

2.7 .4

KATZ

395

368

2.2 .2

KATZ

369

2.2 .3

2.4 .1

2.7 .4

370

2.1.1

DORUFF 174

371

2.1.1

2.2 .2

2.7 .4

372

2.1 .2

2.2 .2

373

2.1.1

2.7 .2

374

2.3.2

2.7.1

2.7 .2

375

2.2 .1

2.2 .2

2.4.1

376

2.1.1

2.1 .3

377

2.1.1

2.6 .2

378

2.5.2 2.6.1

379

2.1 .1

KULIKOWSKI 411

380

2.3.2

CEPICKA 2.5 .2

381 
Comment Report

Number Section

382

2.1 .1

2.5.1

383

2.1.1

2.5.1

384

2.1 .1

DESANTIS

Name

Page

CEPICKA

415

385

2.1 .1

DESANTIS

419

386

2.1 .1

2.1 .2

2.1 .3

2.1 .4

387

2.1 .1

2.7.2

388

2.2.3

2.4 .2

389

2.1 .1

2.1.1

2.7.2

2.7 .4

391

2.1 .1

2.7.4

392

2.1 .1

QUIGLEY

427

393

2.1 .1

2.1.2

394

2.3.2

QUIGLEY

427

395

2.3.1

2.3.2

396

2.1.1

2.3 .2

397

2.2 .3

2.3.2

VEILUVA

VEILUVA

423

VEILUVA 424

EDWARDS 425

EDWARDS 425

QUIGLEY 427

VIROSTEK 436

KATZ 438

KATZ 438 
Comment Report

Number Section

2.5 .1

KATZ

Name

Page

398

399

2.3.2

KATZ

$\mathrm{ROACH}$

2.3.1

2.7 .1

2.7 .2

401

2.3 .2

2.3.2

2.2.2

2.3 .2

2.2 .2

2.3.2

2.3.2

2.5 .1

408

2.1.1

2.7 .2

409

2.1.1

2.2.1

2.3 .2

410

2.3.2

411

2.2 .2

2.3.2

2.4 .2

2.7 .4

412

2.3.2

413

2.2.1

2.5.1

414

2.7.4
QUIGLEY

443

444

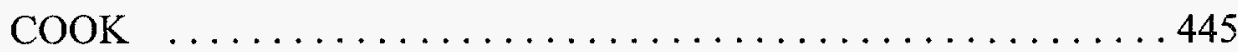

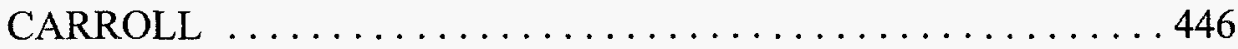

CARROLL ............................446

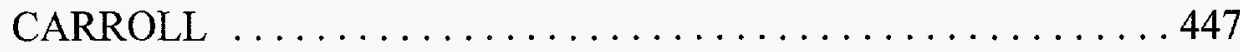

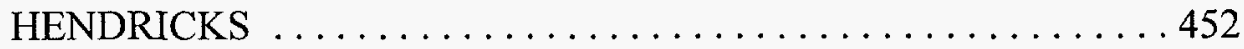

DESANTIS

454

DESANTIS

455

DESANTIS

458

QUIGLEY

460

QUIGLEY 460 460
QUIGLEY 
Comment Report

Number section

$415 \quad 2.3 .1$

2.3.2

$416 \quad 2.3 .2$

417

2.3.2

418

2.7 .4

2.2 .3

2.4 .1

2.7.4

420

2.2 .2

2.1.1

2.1 .2

2.1 .3

2.2 .2

422

2.1 .1

2.1 .2

2.2 .1

2.5 .2

423

2.3 .3

2.3 .2

2.1 .1

2.1 .2

426

2.2 .1

2.3.2

427

428

2.2.2

2.2 .3

2.3.1

2.4 .1

429

2.2 .3

430

2.2.2

2.2 .3

2.4 .1
Name

Page

FELDMAN 464

KULIKOWSKI 465

VIROSTEK 467

KATZ 469

KATZ 469

KILLAR 472

KILLAR 475

BARKER 477

CLOUD 480

GARRY 480

FREE 492

KATZ .499

KATZ 499

KATZ 500

KATZ 501

KATZ 503 
Comment Report

Number Section

431

2.1 .2

2.2 .3

2.3.1

2.3 .2

2.6 .2

433

2.3.2

434

2.2.2

2.2 .3

435

2.1 .3

2.3.1

2.4 .2

436

2.3.2

2.4 .1

437

2.4 .1

438

2.3.2

439

2.2.4

2.3.2

440

2.3.1

441

2.2 .3

442

443

444

445

446

447

448

449

2.2 .3

2.3.2

2.7.4

2.2 .3

2.4 .1

2.3.2

2.4 .2

2.1.3

CAMERON

Name

Page

504

KATZ

505

CARROLL 506

CARROLL 507

QUIGLEY 508

QUIGLEY 509

QUIGLEY 509

QUIGLEY 509

QUIGLEY 510

QUIGLEY .510

BELLMAN 512

QUIGLEY 513

BELLMAN .513

QUIGLEY 514

HUGHES

HUGHES 516

HUGHES 517

NIEDZIELSKI-EICHNER .518 2.4 .3

NIEDZIELSKI-EICHNER 519 
APPENDIX C

Comment Report

Number Section

450

2.3 .2

2.3.1

451

452

2.2 .3

2.7 .2

453

2.4 .1

2.4 .2

454

2.3 .2

2.4.1

2.4 .2

456

2.4.1

2.7 .2

457

2.4.1

458

2.3.2

2.4 .1

459

2.1 .1

2.7.4

460

2.4 .2

2.4 .2

2.3 .1

2.4 .1

2.5 .2

463

2.3 .1

2.2 .3

2.3.2

2.6 .2

465

2.1 .1

2.7.4

466

2.2 .2

2.4 .2

464

467

Name

Page

NIEDZIELSKI-EICHNER .519

NIEDZIELSKI-EICHNER .520

NIEDZIELSKI-EICHNER 520

NIEDZIELSKI-EICHNER .521

HENDRICKS .522

HENDRICKS 523

HENDRICKS 523

HENDRICKS .524

HENDRICKS 524

HENDRICKS 524

\section{HENDRICKS} .525

HENDRICKS 525

EDWARDS 526

EDWARDS 526

EDWARDS 527 
Comment Report

Number Section

468

2.2 .3

2.3.1

2.3 .2

469

2.3.1

2.3 .2

470

2.3.2

2.1 .1

2.2 .3

2.3.1

2.4 .1

473

2.1.2

2.3.1

474

2.3 .1

2.1.1

2.3.1

476

2.3.1

477

2.2 .3

2.3 .1

478

2.3.1

479

2.3 .1

480

2.3.1

481

482

483

484

485

486
2.4.1

2.4 .2

2.4.1

2.4 .1

2.4 .2

2.5 .1

2.3 .2

EDWARDS

Name

Page

529

EDWARDS

530

VEILUVA

533

VEILUVA

VEILUVA

VEILUVA

534

VEILUVA 535

VEILUVA

535

VEILUVA 536

VEILUVA

VEILUVA 537

NIEDZIELSKI-EICHNER $\ldots \ldots \ldots \ldots \ldots \ldots \ldots \ldots \ldots \ldots$

VEILUVA 538

VIROSTEK 539

VIROSTEK 539

VIROSTEK 539

VIROSTEK 539

VIROSTEK 539

VIROSTEK 539 
APPENDIX C

Comment Report

Number Section

487

2.3 .2

2.4 .1

2.5.1

2.5.2

2.7 .2

488

2.7 .4

489

2.2.3

2.4 .2

2.7.2

490

2.4.1

2.7 .2

491

2.4.1

2.7 .2

492

2.5 .2

493

2.1.1

2.1.3

2.2.2

2.2 .3

494

2.1 .3

2.1.3

2.2 .3

2.4 .2

2.7 .2

496

2.1 .3

2.1.1

2.1.3

2.2 .2

498

2.1.1

2.2 .3

499

2.2 .2

2.4.1

2.7.2

500
Name

Page

VIROSTEK

540

VIROSTEK

541

VIROSTEK

VIROSTEK

542

VIROSTEK 543

VIROSTEK 544

MURRAY 545

MURRAY .545

MURRAY 546

MURRAY

549 
Comment Report

Number section

501

2.1.1

2.2 .2

502

2.1.1

2.1.2

2.2 .1

503

2.3.2

2.4 .2

504

2.1.1

505

2.1.1

2.3.2

2.4 .3

2.6.1

2.7 .4

506

2.1.1

2.7 .4

507

2.3.1

2.6.1

508

2.3.1

2.6.1

509

510

511

512

513

514

515

516

517

2.4 .2

2.4 .2

2.7 .4

2.4 .2

2.1.1

2.1.3

2.1.1

2.1 .3

2.1.3

2.4 .2

2.7.3

2.1 .1

MURRAY

Name

Page

550

DESANTIS

550

DESANTIS

DESANTIS

DESANTIS

DESANTIS

554

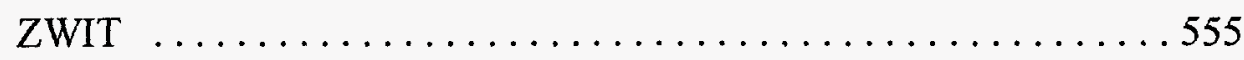

ZWIT

ZWIT

557

ZWIT 510

DORUFF 559

DORUFF

560

DORUFF 562

DORUFF 563

DORUFF 564

KULIKOWSKI 565

KULIKOWSKI 566 


\section{Comment Report}

Number Section

KULIKOWSKI 567

525

2.1.3

2.1 .4

526

KULIKOWSKI 570

527

2.7.1

2.7 .2

528

CEPICKA 573

529

2.3.2

CEPICKA 573

530

CEPICKA 573

531

CEPICKA 575

533

2.2 .2

534

READ

CEPICKA 574

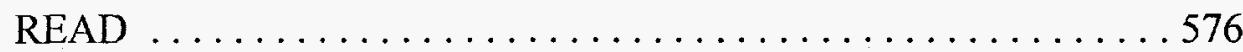

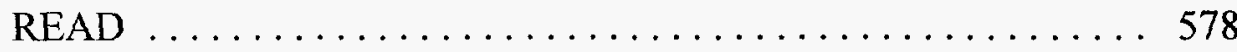

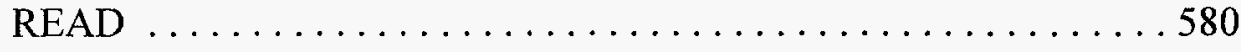




\section{Comment Report}

Number Section

537

2.4 .2

2.4 .1

538

2.3.1

539

2.3 .2

2.4 .3

540

2.3.2

2.7 .4

2.3.2

2.1 .2

2.2 .1

2.4 .3

2.6.1

544

2.3.2

2.6 .2

545

546

2.1.2

2.1.4

2.2 .2

547

2.1.4

2.7 .2

548

549

550

551

552

553

554

555

2.4 .3 2.4 .1 2.4 .1

READ

READ 582

READ 582

READ 583

READ 583

OLSON 591

OLSEN 592

OLSEN 592

OLSEN 593

OLSEN 593

OLSEN

OLSEN 594

OLSEN 596

KILLAR .598

KILLAR 599

KILLAR 599 .604 
Comment Report

Number Section

556

2.1.1

2.1 .2

2.1 .3

557

2.2 .3

2.3.2

558

2.7.4

2.2 .2

559

2.2.3

2.2 .2

2.3 .2

560

2.5 .1

2.7.1

561

562

2.1.4

2.7 .1

563

2.4 .2

2.7 .3

564

2.3 .2

2.4 .2

2.6.1

566

2.7.1

2.7 .4

565

567
Name

Page

HUGHES

606

HUGHES

HUGHES

HUGHES 608

COOK

$\mathrm{ROACH}$ 614

KILLAR 475 
(See instructions on the reverse)

NUREG/CR-6307

\section{TITLE AND SUBTITLE}

Summary of Comments Received at Workshop on Use of a Site Specific Advisory Board (SSAB) to Facilitate Public

Participation in Decommissioning Cases

3.

DATE REPORT PUBLISHED

MONTH

June 1995

4. FIN OR GRANT NUMBER $J 6039$

5. AUTHOR(S)

J. Capl in, G. Page, D. Smith, C. Wibl in

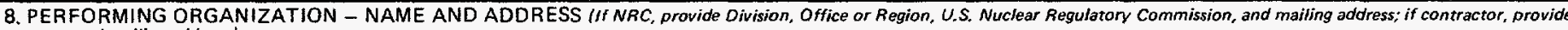
name and mailing address.)

Advanced Systems Technology, Inc.

932 Hungerford Drive

Rockville, MD 20850

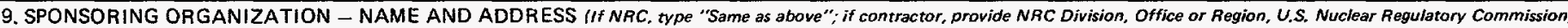
andoilivagdifoss.

Office of Nuclear Regulatory Research

U. S. Nuclear Regulatory Commission

Washington, DC 20555-0001

10. SUPPLEMENTARY NOTES

11. ABSTRACT (200 words or less)

The Nuclear Regulatory Commission (NRC) is conducting an enhanced participatory rulemaking to establish radiological criteria for the decommissioning of NRC-licensed facilities. As part of this rulemaking, On August 20, 1994 the NRC published a proposed rule for public comment. Paragraph 20.1406(b) of the proposed rule would require that the licensee convene a Site Specific Advisory Board (SSAB) if the licensee proposed release of the site for restricted use after decommissioning. To encourage comment the NRC held a workshop on the subject of SSABS on December 6,7 , and 8,1994 . This report summarizes the 567 comments categorized from the transcript of the workshop. The commenters at the workshop generally supported public participation in decommissioning cases. Many participants favored promulgating requirements in the NRC's rules. Some industry participants favored relying on voluntary exchanges between the public and the licensees. Many participants indicated that a SSAB or something functionally equivalent is needed in controversial decommissioning cases, but that some lesser undertaking can achieve meaningful public participation in other cases. No analysis or response to the comments is included in this report.

12. KEY WORDS/DESCR!PTORS (List words or phrases that will assist researchers in Jacating the report.)

decommissioning, radiological criteria, Site Specific Advisory Board (SSAB), public comments

13. AVAILABILITY STATEMENT
unl imited
14. SECURITY CLASSIFICATION
(This Page)
uncl ass ified
(This Regort)
uncl as s if ied
15. NUMBER OF PAGES
16. PRICE

